\title{
Bmf Facilitates Protein Degradation and Reduces Beclin1 Ubiquitination to Inhibit Autophagy Independent of mTOR
}

${ }^{1}$ Monica Delgado-Vergas, ${ }^{1}$ Susan Fort ${ }^{1,2}$ Dereje Tassew, and ${ }^{1,2}$ Yohannes Tesfaigzi

${ }^{1}$ COPD Program, Lovelace Respiratory Research Institute, Ridgecrest Dr., Albuquerque, NM;

${ }^{2}$ Current address, Division of Pulmonary and Critical Care Medicine, Brigham and Women's Hospital, Harvard Medical School, Boston, MA

Running Head: Bmf Facilitates Protein Degradation

Corresponding Author:

Yohannes Tesfaigzi

2425 Ridgecrest Dr. SE

Albuquerque, NM 87108

Tel: (505) 348-9495

Fax: (505) 348-8567

E-mail: ytesfaig@Irri.org

Key words: autophagic cell death/ lung airway epithelial cells/ mucin ubiquitination/ protein accumulation/ p62 and aggresome 


\begin{abstract}
Previous observations suggested that Bcl-2 modifying factor (Bmf) affects autophagy but the underlying mechanisms were unknown. The present studies show that Bmf inhibited the initiation and flux of autophagy in a manner that is independent of the mTOR pathway and inhibition of mTOR increased Bmf expression to temper the autophagic cell death. In mice, emphysema was observed in Bmf-deficient mice, suggesting that Bmf suppresses autophagic cell death of alveolar type II cells. Bmf deficiency increased ubiquitination of Beclin1 with K63 chains and released Beclin1 from Bcl-2. However, Bmf deficiency also increased the levels of polyubiquitinated proteins in general. In mice, Bmf-deficiency robustly increased p62 levels in all tissues analyzed, but LC3-II levels were reduced only in the hearts of old mice. Also, Bmfdeficiency caused persistent mucous cell metaplasia in mice exposed to allergen and increased levels of polyubiquitinated Muc5ac in differentiated airway epithelial cells. The reduction of ubiquitinated proteins was mediated by the BH3- and dynein binding-domains of Bmf. Together, these findings show that the primary role of Bmf is to reduce protein levels and affects K63- and K48-ubiqutination.
\end{abstract}

Keywords: Bcl-2 homology region 3; Bmf, autophagy; proteasomal and lysosomal protein degradation, mucin degradation and ubiquitination; emphysema, fasting, mucous cell metaplasia 


\section{Introduction}

The Bcl-2 family of proteins regulates the intrinsic apoptotic pathway by integrating signals that originate from a variety of cellular stressors. The Bcl-2 subfamily, known as the BCL-2 homology domain 3 only containing (BH3-only) proteins (Bim, Puma, Bid, Bad, Bmf, Bik, Hrk and Noxa) initiate apoptosis in response to DNA damage (Villunger, Michalak et al., 2003) or cytokines (Ekoff, Kaufmann et al., 2007, Mebratu, Dickey et al., 2008). They either bind to neutralize pro-survival Bcl-2 family members or relieve the inhibition of pro-apoptotic Bax and Bak.(Happo, Strasser et al., 2012) While their pro-apoptotic function has been studied well, few studies have focused on the non-cell death-related roles of the Bcl-2 family of proteins. Bcl-2 is implicated in regulating cell cycle entry (Huang, O'Reilly et al., 1997, Linette, Li et al., 1996), and in inhibiting autophagy by binding Beclin1 (Fernandez, Sebti et al., 2018, Pattingre, Tassa et al., 2005). Bad affects insulin secretion and metabolism (Danial, Walensky et al., 2008), Noxa by cross-linking to phospho-HSP27 stabilizes I $\square \mathrm{B} \square$ and regulates inflammation (Zhang, Jones et al., 2018), while Bid by interacting with NOD1, NOD2, and the IkB kinase (IKK) complex facilitates NF-kB activation.(Yeretssian, Correa et al., 2011)

Loss of Bcl-2 modifying factor (Bmf) protects lymphocytes against apoptosis induced by glucocorticoids or histone deacetylase inhibition.(Pfeiffer, Halang et al., 2015) Moreover, bmf $f^{/-}$ mice develop a B cell-restricted lymphadenopathy caused by the abnormal resistance of these cells to a range of apoptotic stimuli. Bmf mRNA is increased upon loss of matrix attachment or disruption of the actin cytoskeleton and Bmf initiates anoikis, while down-regulation of Bmf expression by small interfering RNAs is sufficient to prevent anoikis (Schmelzle, Mailleux et al., 2007). Finally, Bmf-deficiency accelerates the development of gamma irradiation-induced thymic lymphomas, suggesting that Bmf plays a role in apoptosis signaling and can function as a tumor suppressor.(Labi, Erlacher et al., 2008)

At baseline, Bmf mediates fetal oocyte loss in mice at E15.5 and PN1 Primordial follicle numbers remain elevated throughout reproductive life and confer prolonged fertility in $b^{\prime \prime-~}$ females (Liew, Nguyen et al., 2017, Liew, Vaithiyanathan et al., 2014) However, the major phenotype of $\mathrm{bmf}^{-}$mice is a defect in utero vaginal development, including an imperforate vagina and hydrometrocolpos (Hubner, Cavanagh-Kyros et al., 2009). Because vaginal introitus formation requires the apoptosis of the vaginal mucosa (Rodriguez, Araki et al., 1997), it is assumed that Bmf facilitates this formation by apoptotic mechanisms. However, cytochrome $\mathrm{C}$ pathway does not fully account for the pro-apoptotic actions of Bmf because Apaf1 ${ }^{-/}$(Yoshida, Kong et al., 1998) or Casp9 ${ }^{-/}$(Hakem, Hakem et al., 1998, Kuida, Haydar et al., 1998) mice do 
not show this phenotype. Therefore, it is not clear whether Bmf deficiency causes the phenotype due to its apoptotic function or by another mechanism.

We reported that deacetylation of p53, which activates nuclear p53, suppresses Bmf expression. This loss of Bmf diminishes the interaction of Beclin1 and Bcl-2 and thereby facilitates autophagosome formation.(Contreras, Mebratu et al., 2013) However, how this BH3only protein, rather than competing for, enhances the $\mathrm{BH} 3-$ mediated interaction of Beclin-1/Bcl2 to inhibit autophagy was not clear.

Autophagy is a conserved cellular degradation pathway to digest intracellular components during starvation or related stress to provide a source of amino acids for the synthesis of new proteins.(Takeshige, Baba et al., 1992) Phosphorylation of mammalian target of rapamycin (mTOR) inhibits autophagy by controlling UNC-51-like kinase 1 (ULK1) ubiquitination (Nazio, Strappazzon et al., 2013). The activated ULK1/2 kinase complex, including focal adhesion kinase family interacting protein of $200 \mathrm{kDa}$ (FIP200), and subsequent activation of the Beclin1-Vps34-AMBRA1 complex are necessary to initiate phagophore formation (Nazio et al., 2013). Among others, p62 recognizes K63-polyubiquitinated proteins and phase separates proteins into larger condensates to package them into the autophagosomal membrane .(Danieli \& Martens, 2018, Filimonenko, Isakson et al., 2010) Microtubule-associated protein light chain 3 (LC3) I is proteolytically cleaved and attached to phosphatidylethanolamine to form a lipidated LC3-II and facilitate autophagosome maturation. Therefore, conversion of LC3B-I to LC3B-II indicates the presence of mature autophagosomes (Moreau, Ravikumar et al., 2011). Finally, lysosomes fuse with autophagosomes, and the resulting autophagolysosomes and their contents are degraded.

The current study was focused on clarifying the molecular mechanisms how Bmf regulates autophagy. We found that Bmf is a regulator of proteasomal degradation, and that deficiency in Bmf causes accumulation of protein aggregates. Bmf deficiency facilitates Beclin1 ubiquitination by the $\mathrm{K} 63$ polyubiquitin chain to induce autophagy and cause the death of alveolar epithelial cells to cause emphysema in mice. Among other proteins, following injury to the lung, Bmf may also facilitate resolution of mucins in airway epithelia likely by driving their degradation. 


\section{Results}

\section{Bmf inhibits autophagic initiation and flux}

We have previously shown that mouse embryonic fibroblasts (MEFs) or mouse airway epithelial cells (MAECs) from $\mathrm{bmf}^{/-}$compared with $\mathrm{bmf}^{+/+}$mice present with more autophagosomes (Contreras et al., 2013). To investigate whether the accumulated autophagosomes represent a real induction of autophagy or just inhibition of the autophagic flux, we treated cells with bafilomycin A1 (BAF), an inhibitor of the lysosomal degradation. Increased LC3-II levels were observed in vehicle-treated $\mathrm{bmf}^{/-}$compared with $\mathrm{bmf}^{+/+}$MEFs and this difference was enhanced by BAF (Figure 1A). Similar results were observed in $\mathrm{bmf}^{+/-}$compared with $\mathrm{bmf}^{+/+} \mathrm{MEFs}$ after BAF treatment (data not shown), supporting the idea that both the initiation and flux of autophagy were increased in Bmf-deficient cells. In contrast to MEFs, in $\mathrm{bmf}^{\prime-}$ (knockout) compared with $b \mathrm{mf}^{+/+}$MAECs, the difference in LC3-II levels was minimal, even in the presence of BAF (Figure 1B, left blot). However, LC3-II accumulation was more evident in heterozygous $\left(b m f^{+/}\right)$MAECs, especially after BAF treatment (Figure 1B, right blot). Western blot analysis confirmed that Bmf protein is present in $b m f^{+/+}$and $b m f^{+/}$but not in $b m f^{--}$MAECs (Figure S1A), although $>80 \mu \mathrm{g}$ of protein extract was needed to detect Bmf protein. Further, reduced bmf mRNA levels in bmf ${ }^{+-}$MAECs was confirmed by qPCR (Figure S1B). These results support our previous report that induction of autophagy by IFN- $\gamma$ is mediated by reduced Bmf levels (Contreras et al., 2013).

To confirm these findings from murine MEF and MAECs in human airway epithelial cells (HAECs), Bmf expression was suppressed in the HAEC-N3 cells using a lentiviral vector expressing bmf shRNA. Because good antibodies to detect the human Bmf protein are unavailable, we confirmed the bmf knock down by analyzing the bmf mRNA levels by qPCR (Figure 1C). While LC3-II levels are similar in shBmf and shControl (shCtr) cells in the presence of DMSO, BAF treatment caused a greater accumulation of LC3-II in shBmf compared to control cells (Figure 1C). Reducing Bmf levels increased autophagy also in two other nontransformed HAEC lines, HAEC-N1 (Figure S1C) and AALEB cells (Figure S1D).

In contrast, adenoviral expression of Bmf (AdBmf) compared with GFP (AdGFP) in bmf $f^{+/+}$ MAECs reduced accumulation of LC3-II when the autophagic flux was inhibited with BAF although similar levels of LC3-II were observed in the presence of DMSO only (Figure 1D). Similar results were observed in $b m^{+/-}$MAECs when infected with AdBmf compared with AdGFP (Figure S1E). HAEC-N3 cells also showed reduced LC3-II accumulation in AdBmfcompared with AdGFP-infected controls before and after BAF treatment (Figure 1E) as did 
HAEC-N1 cells (Figure S1F). Overexpression of Bmf by transfecting HEK293T cells with a plasmid expressing $\mathrm{Bmf}_{\mathrm{s}}$, also reduced accumulation of LC3-II in the presence of BAF (Figure 1F). These observations show that Bmf inhibits autophagy also in human epithelial cells.

While autophagy is detected in Bmf-deficient cells in culture, the lung and thymus from bmf ${ }^{\prime-}$ compared with $\mathrm{bmf}^{+/+}$mice do not display difference in autophagy markers (Contreras et al., 2013). Even $24 \mathrm{~h}$ after injecting mice with BAF (2 $\mu \mathrm{g}$ per mice) to block the autophagic flux, LC3-II levels were not increased in $\mathrm{bmf}^{+/}$compared with $\mathrm{bmf}^{+/+}$mice in the heart, lung, liver, or brain (data not shown). LC3-II accumulation was not observed in any tissue analyzed in bmf $\mathrm{fl}^{+/}$, $\mathrm{bmf}^{+-}$, and $\mathrm{bmf}^{--}$mice, even with higher doses of BAF (up to $50 \mu \mathrm{g}$ per mice) at 6 or 24 hours post treatment (data not shown). These studies were conducted in 8 - 15 wks old mice. As back-up mechanisms may be more robust to mask effects of Bmf deficiency in young mice, we analyzed tissues from 56 wks old mice and found that LC3-II levels were decreased in the hearts of $\mathrm{bmf}^{+-}$and even more in the heart of $\mathrm{bmf}^{/-}$mice (Figure 1G). However, LC3-II levels in the lungs, kidneys, and spleens from 56 wks old mice still were not affected by Bmf deficiency (data not shown). Although LC3-II levels were decreased in the hearts of Bmf-deficient mice rather than increased, as observed in Bmf-deficient cells in culture, these observations support the overall idea that in aging conditions Bmf affects LC3-II degradation in vivo.

\section{Bmf inhibits autophagy independent of the mTOR pathway}

In resting cells, the Ser/Thr protein kinase mTOR promotes protein translation (Ma \& Blenis, 2009) while suppressing autophagy (Feng, Zhang et al., 2015). mTORC1 senses nutritional and environmental cues, and upon starvation is inhibited to activate autophagy (Nazio et al., 2013). To investigate whether the mTOR pathway is linked to the observed regulation of autophagy by Bmf, we inhibited mTOR by treating cells with pp242, a selective ATP-competitive inhibitor of mTOR, and analyzed the LC3 conversion in $b \mathrm{bf}^{+/+}, \mathrm{bmf}^{+-}$and $\mathrm{bmf}^{--}$MEFs. mTOR activity was efficiently inhibited by pp242 in $\mathrm{bmf}^{+/+}$and $\mathrm{bmf}^{+/-}$MEFs, as detected by decreased amount of the phosphorylated form of P70S6K, a substrate for the mTORC1 kinase activity (Figure S2A). This mTOR inhibition caused accumulated LC3-II in $\mathrm{bmf}^{+/+}, \mathrm{bmf}^{+/-}$and $\mathrm{bmf}^{/-}$ MEFs in the presence of BAF (Figure S2A). However, LC3-II levels in both vehicle- and pp242treated cells were higher in $b^{\prime+/} f^{-}$(Figure S2A, left blot) and in $b m f^{--}$(Figure S2A, right blot)

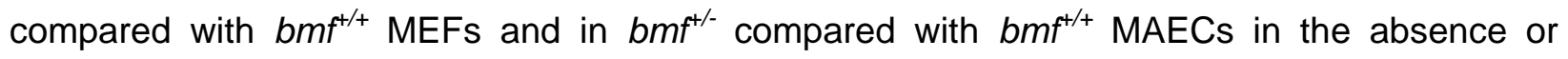
presence of BAF (Figure 2A). Nutrient deprivation for 1 hour, another way to inhibit mTOR activity (Levine \& Klionsky, 2004, Tasdemir, Maiuri et al., 2008), also effectively decreased the phospho-P70S6K levels, indicating mTOR inhibition (Figure S2B) and resulted in increased 
LC3-II accumulation in $\mathrm{bmf}^{-/}$compared with $\mathrm{bmf}^{+/+}$MEFs in the presence of Baf (Figure S2B). The same results were observed in $\mathrm{bmf}^{+/}$compared with $\mathrm{bmf}^{+/+}$MAECs after starvation (Figure 2B). Collectively, these results suggest that Bmf inhibits autophagy independent of the mTOR pathway.

Because Tsc2 protein is an endogenous mTOR inhibitor (Dibble \& Cantley, 2015), Tsc2 ${ }^{-/}$cells have hyperactivation of mTOR as detected by high levels of phospho-P70S6K protein when compared with $\mathrm{Tsc2}^{+/+}$cells (Figure S2C). As expected, Tsc2 $2^{-/}$cells showed less LC3-II levels after BAF treatment compared with $\mathrm{TsC}^{+/+}$cells (Figure S2C). Therefore, we infected $T s c 2^{-/-}$ cells with AdGFP or AdBmf to investigate whether Bmf affects autophagy when mTOR is hyperactivated. We observed that BAF treatment of $T s c 2^{-/}$cells increased the LC3-II levels in control cells (AdGFP infected) and in cells expressing Bmf (AdBmf infected), but the accumulation of LC3-II was less when cells were expressing Bmf (Figure 2C), again supporting that Bmf inhibits autophagy irrespective of mTOR activation.

We further investigated whether Bmf overexpression reduces autophagy in different cell types when mTOR is inhibited. Therefore, MAECs were either infected with AdGFP or AdBmf and treated with pp242, to inhibit mTOR, and with BAF, to inhibit lysosomal degradation. Bmf over expression in $\mathrm{bmf}^{+/+}$MAECs reduced pp242-induced LC3-II accumulation in the presence of BAF (Figure 2D). Similar results were observed when Bmf levels were increased in $\mathrm{bmf}^{+/}$or reexpressed in $b m f^{\prime-}$ MAECs and cells were treated with pp242 and BAF (Figure S2D). When HAEC-N3 (Figure 2E) and HAEC-N1 (Figure S2E) were treated with pp242, the accumulated LC3-II levels were reduced in cells expressing Bmf compared with cells expressing GFP. These results suggest that Bmf inhibits autophagy downstream mTOR activation in murine and human cells.

Contrary to Bmf enhancing cell death, as was previously reported (Grespi, Soratroi et al., 2010, Labi et al., 2008, Puthalakath, Villunger et al., 2001), we had previously reported that survival of $\mathrm{bmf}^{/-}$compared with $\mathrm{bmf}^{+/+}$MEFs is reduced when cells are starved or treated with pp242 for 24h (Contreras et al., 2013). Our observation suggested that by inhibiting autophagy, Bmf may protect from cell death induced by enhanced autophagy activation that occurs when mTOR is inhibited for prolonged periods. In support of this idea, Bmf mRNA expression was robustly increased both after pp242 treatment and starvation for $24 \mathrm{~h}$ in wild type MAECs and in HAECN3 cells (Figure 2F). Further, starvation or pp242 treatment for 4 hours induced bmf mRNA levels by 1.5-2.0 fold in $\mathrm{bmf}^{+/}$MAECs but not in $\mathrm{bmf}^{+/+}$MAECs, supporting the idea that increased Bmf expression may be needed to protect from cell death when mTOR is inhibited 
(Figure 2G). Additionally, bmf mRNA was also increased in $b m f^{+/+}$MEFs by almost 4- and 8fold after prolonged pp242 treatment and starvation, respectively (Figure S2F). Similar increases in Bmf mRNA were also observed in HAEC-N1 and AALEB cells after 24 hours of mTOR inhibition or starvation (Figure S2G). As expected, survival was reduced in bmf $\mathrm{bm}^{\prime-}$

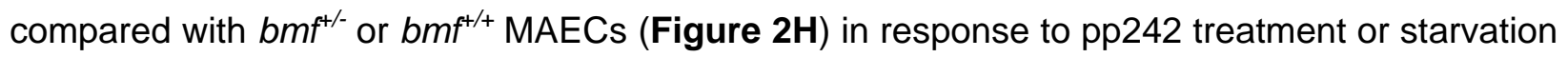
over 24 hours. These findings further confirmed the protective role of Bmf expression from autophagy-induced cell death, likely by tempering the extent of autophagy induced by mTOR inhibition. Consistent with Bmf promoting survival, we observed extensive emphysema in the lungs of $\mathrm{bmf}^{-/}$and $\mathrm{bmf}^{+/-}$compared with $\mathrm{bmf}^{+/+}$mice (Figure 2l). Therefore, persistent autophagy in the lungs may enhance death of alveolar cells in Bmf-deficient mice.

Our observations that Bmf may dampen autophagy when mTOR is inhibited suggested that fasting of Bmf-deficient mice may show a weight loss different than wild-type mice. Bmf ${ }^{\prime-}$ mice showed reduced weight loss compared with $b \mathrm{mf}^{+/+}$mice after $30 \mathrm{~h}$ of fasting (Figure $\mathbf{2} \mathbf{J}$ ).

\section{Bmf enhances proteasomal degradation}

The observations that Bmf suppresses autophagy downstream mTOR lead us to investigate the underlying mechanisms for the autophagic inhibition by Bmf. It is known that a PI3 kinase needs to be activated downstream mTOR to trigger the initiation of autophagy. This PI3K activity requires Beclin1. Because we have previously observed that Beclin1 levels are increased in $\mathrm{bmf}^{\prime-}$ compared with $\mathrm{bmf}^{+/+}$MEFs and MAECs (Contreras et al., 2013), we wanted to test the hypothesis that Bmf deficiency may cause an imbalance between Beclin1 and Bcl-2 by increasing Beclin1 levels. Similar to what we previously reported in bmf ${ }^{-}$MAECs, Beclin1 levels were also higher in $b m f^{+/-}$compared with $b \mathrm{mf}^{+/+}$MAECs; however, Bcl-2 protein levels were also higher in both $\mathrm{bmf}^{+/-}$and $\mathrm{bmf}^{--}$cells (Figure 3A). Therefore, we decided to investigate whether Bmf deficiency also increases the levels of other proteins. Interestingly, levels of proteins not related to autophagy regulation, including mitochondrial proteins like mitofusin 2 (Mfn2), cytochrome c (Cyt c) and Cox IV, the apoptotic protein Bak, the cytoskeleton protein dynein light chain 1/2 (DLC1/2), and the ER-associated protein BiP, were also higher in $\mathrm{bmf}^{/-}$and $\mathrm{bmf}^{+/}$compared with $\mathrm{bmf}^{+/+}$MAECs (Figure 3A, and Figures S3A, B, C). Another protein that was consistently increased in $b m f^{+-}$and $b m f^{--}$MAECs was p62 (Figures 3A and S3A). Beclin1, p62, and DLC1/2 were also elevated in HAEC-N3 and HAEC-N1 cells when Bmf levels were suppressed using shBmf (Figure S3D). The possibility that Bmf may affect protein stability was further strengthened by the observation that Beclin1 levels were reduced when Bmf levels were increased by AdBmf infection in $b m f^{+/+}, b m f^{+/}$or $b m f^{/-}$MAECs (Figure 3B). 
As was observed in $b m^{+/-}$and $b m f^{--}$MAECs (Figure 3A), p62 levels were also increased in the lungs of $\mathrm{bmf}^{+/}$and $\mathrm{bmf}^{/-}$mice at 8 wks (Figure $3 \mathbf{C}$ ) and this p62 increase was more evident in $\mathrm{bmf}^{/ /}$mice at $15 \mathrm{wks}$ of age (Figure S3E). BAF did not modify p62 levels in the tissues analyzed (data not shown), but age robustly increased p62 levels (Figure S3F) and the lungs, hearts, kidneys and spleens from $\mathrm{bmf}^{+/}$or bmf $\mathrm{fl}^{/-}$show higher levels of $\mathrm{p} 62$ compared with $\mathrm{bmf}^{+/+}$ mice when mice are 56 wks old (Figures 3C, S3G). Bmf deficiency caused a significant increase of p62 in vivo than in cultured cells (Figures 3A and 3C). Increased p62 levels were also evident in the heart, liver and muscle from $\mathrm{bmf}^{/-}$mice compared with $\mathrm{bmf}^{+/+}$mice that were fasted for $30 \mathrm{~h}$ (Figure $\mathbf{S 3 H}$ ). We found that other proteins were also elevated in different tissues from $\mathrm{bmf}^{+-}$mice at 8 or at 15 weeks (data not shown). Most of the proteins analyzed (including Bcl-2, CoxIV and BiP) were detected to be at even higher levels in Bmf-deficient lungs, hearts, kidneys and spleens from 56 weeks old mice (Figures 3C, and S3I).

As Bmf having a role in protein stability has not been reported before, we decided to explore this role by treating $\mathrm{bmf}^{+-}$and $\mathrm{bmf}^{+/+}$MAECs with MG132. We observed accumulation of several proteins in $\mathrm{bmf}^{+/+}$but not in $\mathrm{bmf}^{+/}$MAECs, consistent with an inhibition of their proteasomal degradation (Figures 3D, and S3J, S3K). These observations suggested that proteasomal degradation is disrupted in Bmf-deficient cells. When proteasomal degradation is inhibited, the accumulated proteins are confined in inclusion bodies as aggregates to decrease their cell toxicity (Hillert, Brnjic et al., 2019, Takahashi, Kitaura et al., 2018). Therefore, we investigated whether $\mathrm{bmf}^{+/}$MAECs present with accumulation of proteins in the "insoluble fraction" that is solubilized only with high concentrations of SDS and DDT. We found that $\mathrm{bmf}^{+/-}$compared with $\mathrm{bmf}^{+/+}$MAECs show increased accumulation of several proteins also in the "insoluble fraction" (Figures 3E and S3L). We also found that the "insoluble fractions" from the Bmf-deficient lungs (Figure 3F), liver, and muscle (data not shown) present with increased p62 compared with wildtype mice. Also, bmf $f^{++}$MAECs present with more proteins in the "insoluble fraction" after treatment with MG132 (Figure S3M), confirming that it is a phenotype associated with proteasomal degradation inhibition. These observations suggest that Bmf facilitates proteasomal degradation.

In another set of experiments, we compared levels of total poly-ubiquitinated proteins in $\mathrm{bmf}^{+/}$, $\mathrm{bmf}^{+-}$, and $\mathrm{bmf}^{--}$MAECs. Poly-ubiquitinated proteins were increased in $\mathrm{bmf}^{+-}$and $\mathrm{bmf}^{/-}$ compared with $\mathrm{bmf}^{+/+}$MAECs (Figure 3G). Also, wild type MAECs treated with MG132 accumulated poly-ubiquitinated proteins to levels observed in non-treated bmf $^{+/}$MAECs (Figure 3G), further supporting the idea that Bmf enhances proteasomal degradation. We also found 
that $\mathrm{bmf}^{+/-}$and $\mathrm{bmf}^{--}$compared with $\mathrm{bmf}^{+/+}$MAECs present with more K-48 poly-ubiquitination (Figure $3 \mathbf{H}$ ), the prominent ubiquitination associated with proteasomal degradation.(Yau \& Rape, 2016) When HEK293T cells were co-transfected with HA-K48-ubiquitinin and Bmf, the total K48-poly-ubiquitination of proteins was reduced compared with cells not transfected with Bmf as control (Figure 3I). Also, the lungs from $b f^{+/}$or $b m f^{/-}$compared with $b m f^{+/+}$mice showed more total K-48-polyubiquitinated proteins both in the "soluble" and "insoluble" fractions (Figure 3J). Together, these findings point to the role of Bmf facilitating proteasomal degradation in vitro and in vivo.

\section{Bmf affects degradation of mucins in mice and in differentiated MAECs}

We decided to investigate whether the role of Bmf in inhibiting protein degradation in vivo will be more evident following an injury to the lung. We have previously shown that in mice, prolonged exposure to ovalbumin (OVA) as an allergen causes the resolution of mucous cell hyperplasia (Shi, Fischer et al., 2002, Tesfaigzi, Fischer et al., 2002). Consistent with previous observations, the number of mucous cells was reduced in $\mathrm{bmf}^{+/+}$mice 15 days after the OVA exposure, but resolution was abrogated in $\mathrm{bmf}^{\prime-}$ mice (Figure 4A). Because of our findings that Bmf enhances proteasomal degradation, we decided to investigate whether Bmf plays a role in reducing stored muco-substances by proteolytic degradation of mucins. Using differentiated MAECs, we first established an in vitro system that reflects what was observed in mice. Therefore, $\mathrm{bmf}^{+/+}$and $\mathrm{bmf}^{+/-}$MAECs were differentiated on air-liquid interface cultures and treated with IL-13 for $14 \mathrm{~d}$ to induce mucin production. Another set of cultures were treated with IL-13 for 14 days and kept without treatment for an additional 7 days. As detected by immunofluorescence, $\mathrm{bmf}^{+/-}$compared with $\mathrm{bmf}^{+++}$MAECs showed more Muc5ac-positive cells after 7 days of recovery post IL-13 treatment (Figure 4B). In addition, although Muc5ac mRNA levels were similar in untreated $\mathrm{bmf}^{+/+}, \mathrm{bmf}^{+-}$and $\mathrm{bmf}^{--}$differentiated MAECs (Figure 4C), Western blot analysis of the mucins first separated in a $0.8 \%$ agarose gel, transferred to a nitrocellulose membrane and developed with antibodies anti Muc5ac showed that bmf $f^{/-}$ compared with $\mathrm{bmf}^{+/+}$MAECs displayed higher Muc5ac protein levels both at baseline and at 7 d post IL-13 treatment (Figure 4D). In addition, mucins in $\mathrm{bmf}^{/-}$compared with $\mathrm{bmf}^{+/+}$MAECs showed a higher signal with anti-ubiquitin antibody, (Figure 4D). Also, antibodies to K48ubiquitin showed a higher signal in mucins from $\mathrm{bmf}^{/-}$compared with $\mathrm{bmf}^{+/+}$MAECs under control or IL-13 stimulated conditions (Figure 4E), suggesting that mucin degradation may be delayed by Bmf deficiency. Similarly, differentiated bmf $^{+-}$MAECs showed more Muc5ac and more K48-ubiquitinated mucins than wild type cells at baseline (Figure S4A) and after IL-13 
treatment (Figure S4B). Differentiated $b^{\prime--}$ compared with $b m^{+/+}$MAECs also showed accumulation of other proteins (Figure 4F). As expected, differentiated $\mathrm{bmf}^{+/-}$MAECs showed accumulation of several proteins compared with $\mathrm{bmf}^{+/+}$MAECs at baseline (Figure S4C) and after IL-13 treatment (Figure S4D). IL-13 treatment reduced Bmf mRNA levels in both differentiated $\mathrm{bmf}^{+/+}$and $\mathrm{bmf}^{+/-}$MAECs (Figure S4E), supporting the idea that reduced Bmf is correlated with increased Muc5ac protein levels.

\section{Bmf inhibits autophagy by decreasing Beclin-K63 ubiquitination}

Because our findings strongly suggest that Bmf facilitates proteasomal degradation both in vitro and in vivo, we explored the hypothesis that Bmf may be linking the proteasomal degradation and the autophagy pathways. We investigated whether Bmf inhibits autophagy by stabilizing the Beclin1/Bcl-2 complex by preventing Beclin1 from being released in its activate form to initiate the autophagosome formation (Pattingre et al., 2005). Immunoprecipitation with antiBeclin1 antibodies resulted in reduced $\mathrm{Bcl}-2$ protein from $\mathrm{bmf}^{+/-}$(heterozygote) compared with $b m f^{+/+}$MAEC extracts, confirming that Bmf stabilizes the Beclin1/Bcl-2 complex (Figure 5A). Similarly, reduced Bcl-2 binds Beclin1 in $b m f^{--}$(knockout) compared with $b m f^{+/+}$MAECs (Figure S5A), suggesting that Beclin1 is released from Bcl-2 as Bmf levels are reduced.

We have previously detected the interaction of Bmf with Beclin1 and Bcl-2 in wild type MEFs (Contreras et al., 2013). As endogenous Bmf is only faintly detected by Western blotting in extracts prepared from MAECs (Figure S1A), we decided to increase the expression of Bmf using adenoviral expression vector in $b m f^{-\alpha}$ MAECs and analyze Beclin1-interacting proteins by immunoprecipitation compared with Ad-GFP-infected controls. The Beclin1/Bcl-2 interaction was more abundant in cells expressing Bmf (Figure 5B). However, although Bmf was expressed, as shown in the input, Bmf protein was not detectable in the immunoprecipitates with anti-Beclin1 antibodies. Similarly, infecting HEK293T cells with AdBmf to increase Bmf expression resulted in increased interaction of Beclin1/Bcl-2 when the IP is performed with antiBcl-2 antibodies (data not shown), although Bmf was not detected in the IP. These findings may suggest that Bmf easily dissociates from the complex during the immunoprecipitation process.

Because inhibition of autophagy occurs when Beclin1 interacts with the endoplasmic reticulum (ER)-localized Bcl-2 (Pattingre et al., 2005), we designed an experiment overexpressing ERlocalized Bcl-2 (ER Bcl-2) by transiently transfecting HEK293T cells and $2 \mathrm{~h}$ later infecting them with AdBmf. Immunoprecipitation with anti-Bcl-2 antibodies showed that Bmf enhances ER-Bcl- 
2 interaction with Beclin1 (Figure S5B), and Bmf was detected in the IP revealing the interaction of Bmf with ER-localized Bcl-2.

We further investigated whether autophagy is activated in Bmf-deficient cells by promoting Beclin1 release from $\mathrm{Bcl}-2$. We used the $\mathrm{BH} 3$ mimetic ABT-263 that releases Beclin1 from $\mathrm{Bcl}-$ 2 due to its higher affinity to Bcl-2.(Maiuri, Zalckvar et al., 2007) ABT-263 treatment increased LC3-Il levels in ${b m f f^{+/+}}$but not in bmf $^{+/-}$MAECs (Figure 5C), supporting the idea that activation of autophagy may occur by releasing Beclin1 from Bcl-2 either by the presence of a $\mathrm{BH} 3$ mimetic compound or by reduced Bmf levels. The involvement of the proteasomal activity by Bmf on autophagy regulation was examined by using MG132. Upon 6h of MG132 treatment, LC3-II increased in $\mathrm{bmf}^{+/+}$MAECs to levels similar to what was observed in $\mathrm{bmf}^{+/-}$MAECs treated with DMSO as vehicle control (Figure 5D). As MG132 blocks proteasomal function, these findings further support the idea that the Beclin1/Bcl-2 interaction was affected by Bmf-deficiency due to the inhibition of the proteasome.

When the proteasomal degradation is disrupted, certain E3 ligases increase the K63-linkage ubiquitination of many proteins.(Lim, Chew et al., 2013) When Beclin1 is ubiquitinated by K63linkage, the Beclin1/Bcl-2 interaction is disrupted and Beclin1 is released to activate the PI3P kinase activity and autophagy is activated.(Shi \& Kehrl, 2010a) Therefore, we investigated whether this process may be responsible for the activated autophagy in Bmf-deficient cells. Overall, K63-linked ubiquitination is increased in $\mathrm{bmf}^{{ }^{--}}$and $\mathrm{bmf}^{+/-}$compared with $\mathrm{bmf}^{+/+}$MAECs (Figure 5E). K63-linked ubiquitination is also increased in $\mathrm{bmf}^{/-}$compared with wild type MEFs (Figure S5C). Also, HEK293T cells that co-express HA-K63-Ubiquitin and Bmf show reduced K63-poly-ubiquitination compared with cells not overexpressing Bmf (Figure 5F). In addition, K63-polyubiquitinated proteins are increased in the lungs of $\mathrm{bmf}^{+/-}$or $\mathrm{bmf}^{/-}$compared with $\mathrm{bmf}^{+/+}$ mice in both the "soluble" and "insoluble fractions" (Figure 5G).

Immunoprecipitation with anti-Beclin1 antibodies confirmed increased K63-linked ubiquitination of Beclin1 in bmf $f^{+-}$compared with $b m f t^{+/}$MAECs (Figure $5 \mathbf{H}$ ). Further, immunoprecipitation of Beclin1 from bmf ${ }^{\prime-}$ MAECs transfected with a Bmf-expression plasmid showed reduced K63ubiquitination of Beclin1 (Figure 5I). However, likely due to the low transfection efficiency in MAECs, expressed Bmf was not detected by Western blotting. Collectively, these results demonstrate that in MAECs, Bmf-deficiency not only increases Beclin1 levels but also facilitates K63 ubiquitination of Beclin1 to cause the release of Beclin1 from Bcl-2 and thereby activate autophagy.

\section{Dynein Binding and BH3 Domains of Bmf affect K63-ubiquitination and autophagy}


To identify the Bmf protein domains responsible for reducing K63-ubiquitination, Bmf mutants in the dynein-binding domain (DBD mutant) or the $\mathrm{BH} 3$ domain (BH3 mutant) were generated within the $\mathrm{Bmf}_{\mathrm{S}}$ isoform (Figure 6A). Transfected HEK293T cells showed two Bmf bands, with the $\mathrm{BH} 3$ mutant expressing more of the larger band and both the DBD mutant and the wild type expressing more of the smaller band (Figure 6B). When co-transfected along with HA-K63ubiquitin expression plasmid, both the DBD and $\mathrm{BH} 3$ mutants were less efficient in reducing total K63-ubiquitinaton than wild-type Bmf (Figure 6C). Immunoprecipitations with anti Beclin1 antibodies showed reduced K63-ubiquitinated Beclin1 in cells transfected with wild-type compared with Bmf mutants (Figure 6D). Also, the Beclin1/Bcl-2 interaction increased more by wild-type Bmf than by the Bmf mutants (Figure 6D). Because we did not observe changes in LC3-II between HEK293T cells expressing wild-type or mutant Bmf forms, we suspected that endogenous Bmf in HEK293T cells may play a role. Therefore, we transfected $\mathrm{bmf}^{-}{ }^{-} \mathrm{MEFs}$ with these constructs and detected Bmf only in the "insoluble fraction"; also, Bmf mRNA was detected only in cells transfected with w.t., BH3, and DBD mutants (Figure S6A). Expression of Bmf was confirmed by detecting Bmf mRNAs by qPCR (data not shown). Despite low Bmf protein levels detected, cells transfected with wild-type Bmf showed decreased BAF-induced LC3-II accumulation compared with cells transfected with the BH3 or DBD mutants, with the DBD mutant showing the highest LC3-II levels (Figure 6E). We have shown previously that $\mathrm{bmf}^{/}$MEFs present higher numbers of LC3 puncta than wild type MEFs when overexpressing LC3-Cherry (Contreras et al., 2013). While bmf ${ }^{-}$MEFs also present with a high number of LC3 puncta (Figure 6F), the number of LC3 puncta (Figure 6F) as well as their intensity (Figure S6B) were reduced when cells were transfected with wild-type Bmf but not with the BH3 or DBD mutant forms. These results suggest that the BH3 and DBD domains of Bmf are required for the effects of Bmf on protein ubiquitination and autophagy. 


\section{DISCUSSION}

The present study shows that the main role of $\mathrm{Bmf}$ is to facilitate the degradation of many proteins and Bmf-deficiency, by increasing levels of ubiquitinated proteins causes reduced protein degradation and increased autophagy. Therefore, in Bmf deficient cells, ubiquitination of Beclin1 by the K63-linked chain causes the release of Beclin1 from Bcl-2 to initiate autophagy. This finding explains the seemingly contradictory role of $\mathrm{Bmf}$ as a $\mathrm{BH}$-only protein, rather than competing for the $\mathrm{BH} 3$ binding groove of $\mathrm{Bcl}-2$, enhances the Bcl-2/Beclin1 interaction.

Starvation of cells causes Beclin1 to be ubiquitinated at Lys437 via a K63 linkage. Beclin1 is also K63-ubiquitinated after TLR4 stimulation in macrophages, but this ubiquitination occurs on Lys117.(Shi \& Kehrl, 2010b) In contrast, WASH negatively regulates autophagy through suppression of Beclin1 K63-polyubiquitination.(Xia, Wang et al., 2013). Phosphorylation of USP14 by Akt removes K63 ubiquitin linkages including that of Beclin1.(Xu, Shan et al., 2016) Whether Bmf participates in deubiqutinating both sites on Beclin1 will be studied in the future.

Mutations on the $\mathrm{BH} 3$ or DBD domains of Bmf compromise the $\mathrm{K} 63$ ubiquitination of Beclin1. It is possible that the $\mathrm{BH} 3$ and DBD mutations affect Bmf function because of conformational changes. However, because the DBD attaches Bmf to the actin-myosin $\mathrm{V}$ filaments through DLC2, it is possible that Bmf may act as a sensor for stimulators of the cytoskeletal structures to regulate protein degradation. Several deubiquitinases (DUBs) have been associated with the cytoskeletal machinery of the cell, including USP33 (Li, D'Angiolella et al., 2013) and ataxa3.(Burnett \& Pittman, 2005)

This report focused on mutations of $\mathrm{Bmf}_{\mathrm{S}}$, but did not explore the $\mathrm{Bmf}_{\mathrm{L}}$ or $\mathrm{Bmf}_{\mathrm{CuG}}$ isoforms. Whether these protein variants, that originate from different transcriptional start sites. may determine the cell death or proteasomal roles of Bmf needs further investigation. It is possible that the relative level of each Bmf isoform determines its role in protein degradation and autophagy, generating an effect that is tissue- and cell type-dependent.

Interestingly, $\mathrm{bmf}^{+/-}$compared with $\mathrm{bmf}^{--}$MAECs present with more Beclin1 levels; therefore, most of our studies used $\mathrm{bmf}^{+/-}$cells. Also, the inhibitory role of Bmf on autophagy becomes evident only under stress conditions, such as cells maintained in dispersed culture conditions. Surprisingly, when MAECs were differentiated on Transwell cultures the levels of several protein were increased in Bmf deficient cells, but Beclin1 levels remained unchanged in $\mathrm{bmf}^{/-}$and $\mathrm{bmf}^{+/-}$ compared with $\mathrm{bmf}^{+/+}$genotypes. Similarly, the levels of Beclin1 in the lungs or other tissues were not different among $b f^{+/+}$and $b m f^{+-}$or $b m f^{/-}$mice (data not shown). Autophagy, as 
detected by changes in the LC3-II levels, was not observed in most tissues of Bmf-deficient mice, except for in the heart of old mice, where LC3-II levels were reduced in the Bmf-deficient mice. These findings suggest that compensatory mechanisms that reduce Beclin1 ubiquitination may be activated when Bmf is absent. Fasting in mice does not induce autophagy uniformly in all tissues, suggesting that regulation of autophagy is organ specific.(Yoshimoto, Shibata et al., 2014) Accordingly, while accumulation of p62 in Bmfdeficient mice was detected in all tissues analyzed, autophagy phenotype by Bmf deficiency was detected only in the heart.

The fact that Bmf deficiency increases LC3-II levels in cultured cells but reduces LC3-II levels in heart tissue may be explained by an enhanced autophagic flux in mouse tissues. Also, we found reduced weight loss during fasting of $b m f^{/-}$compared with $b m f^{+/+}$wild-type mice. In contrast, previous findings show that reduced autophagy is associated with reduced weight loss in fasting mice.(Fernandez, Barcena et al., 2017) Therefore, reduced weight loss during fasting in Bmf deficient mice may be a result of the disrupted protein degradation, the phenotype that is predominantly observed in many tissues. Future studies will investigate the role of protein degradation and weight loss during fasting.

The observation that Bcl-2, DLC1/2, BiP, Mfn2 and p62 levels are increased in several tissues (spleen, brain, thymus, lung) from $\mathrm{bmf}^{+-}$compared with $\mathrm{bmf}^{+/+}$mice as young as 8-15 wks old suggests that the major function of Bmf in vivo is to regulate protein degradation. The unfolded protein response (UPR) is crucial for selectively degrading misfolded proteins.(Grice \& Nathan, 2016) When the UPR is overloaded to degrade the K48-tagged proteins, K63-linked ubiquitination initiated as a signal to promote sequestration of proteins into aggresome.(Olzmann \& Chin, 2008) Given that K63-linked polyubiquitination of proteins is generally uncoupled from the UPR, enhanced cellular ubiquitin modification of proteins via K63 promotes their accumulation and subsequent aggregation in the cell (Lim et al., 2013). We also found that Bmf deficiency enhances aggresome formation, further supporting that Bmf reduces K63-linked polyubiquitination.

The most striking phenotype of the Bmf-deficient mice is the increase in p62, as it was observed in cultured cells, but even more prominently in all tissues analyzed. Accumulation of p62 is delayed in $\mathrm{bmf}^{-/}$compared with $\mathrm{bmf}^{+/}$mice and fasting did not affect the higher levels of p62 in the heart, muscle and liver of $b m f^{--}$compared with $b m f^{+/+}$mice, both in the "soluble" and "insoluble" fractions. Proteasome inhibition induces rapid p62 expression in cells, which enhances survival by sequestering ubiquitinated proteins in inclusion (Sha, Schnell et al., 2018) 
and to sequester and attach the cargo to LC3-tagged isolation membranes for phagosome formation (Zaffagnini, Savova et al., 2018). Accumulation of p62 in Bmf-deficient mice remains unaffected when fasting over 30h, suggesting that the role of Bmf in proteasomal degradation inhibition is not modified by inhibiting the mTORC1 pathway. The observation that generally ubiquitinated proteins are increased by Bmf-deficiency suggests that the protein degradation system is affected by Bmf deficiency to such an extent that in addition to increased autophagy sequestration of proteins in aggresomes may be needed by increasing p62 protein levels. How Bmf deficiency leads to increased p62 levels is not known.

Metaplastic mucous cells and the amount of stored mucosubstances remained unchanged in $\mathrm{bmf}^{/-}$mice and did not resolve following $15 \mathrm{~d}$ of challenge with ovalbumin, while the number of metaplastic mucous cells were reduced in $\mathrm{bmf}^{+/+}$mice. Our findings suggest that the metaplastic mucous cells remained because of lack of degradation of mucins. We found that more ubiquitinated mucins are present in $\mathrm{bmf}^{/-}$and $\mathrm{bmf}^{+/-}$compared with $\mathrm{bmf}^{+/+}$differentiated MAEC cultures, suggesting that mucins may undergo degradation even under normal conditions. Intracellular levels of mucins are believed to be regulated by secretion. (Innes, Woodruff et al., 2006, Roy, Livraghi-Butrico et al., 2014 , Singer, Martin et al., 2004) Also, in airway epithelial cells, IL13 activates autophagy to regulate secretion.(Dickinson, Alevy et al., 2016) This is the first report to show that mucins are ubiquitinated. Mucins are stored in vesicles tethered to myosin fibers (Lin, Fang et al., 2010, Raiford, Park et al., 2011) and we showed that the ubiquitination of mucins is increased when Bmf is deficient. Because mucins are highly glycosylated proteins, ubiquitination and degradation of these complex molecules requires $E$ ligases that transfer the ubiquitin to these huge glycoproteins. An E3 ubiquitin ligase that recognizes sugar chains, Fbx2, that is primarily found in neuronal cells (Yoshida, Chiba et al., 2002) and one that recognizes $N$-glycan, Fbs2 (called Fbx6b or FBG2 previously) (Yoshida, Tokunaga et al., 2003) have been identified. Approximately 70 genes for F-box proteins, and at least five homologous F-box proteins containing a conserved motif in their C-termini are thought to recognize sugar chain of N-linked glycoproteins.(Yoshida \& Tuder, 2007) Among these, Fbs1 and Fbs2 are perhaps involved in the endoplasmic reticulum-associated degradation pathway. Whether these proteins are involved in the degradation of mucins remains to be investigated. However, modifying the degradation of mucins may provide a novel approach to reduce epithelial stored mucosubstances in chronic lung diseases before their secretion obstructs the airways. 
We found that Bmf-deficient mice present with emphysema already at 8 wks of age. Cigarette smoke, by inducing PINK, mediates autophagy-dependent elimination of mitochondria (mitophagy) and necroptosis of alveolar epithelial cells to cause emphysema in mice (Mizumura, Cloonan et al., 2014). Another study found that cigarette smoke causes cell death of alveolar cells by decreasing Bcl-2/Beclin1 interaction and inducing autophagy.(Qin, Gao et al., 2019) In fact, basal level of autophagy is always present in type II alveolar cells and is increased after a fasting period (Mizushima, Yamamoto et al., 2004). Transgenic expression of IFN $\gamma$ in airways driven by the CCSP promoter causes emphysema (Wang, Zheng et al., 2000) and we showed that IFN $\gamma$ causes autophagy in airway epithelial cells by suppressing Bmf expression.(Contreras et al., 2013) Human alveolar epithelial cells treated with cigarette smoke extract have increased polyubiquitinated proteins and cell death, and mice exposed to cigarette smoke show impaired proteasomal activity and accumulation of polyubiquitinated proteins in the soluble and insoluble protein fractions.(van Rijt, Keller et al., 2012) Further, p62 levels are higher in smokers with severity of emphysema.(Tran, Ji et al., 2015) Together with the findings in the current study that reduced Bmf levels increase p62 levels and enhance the autophagic cell death of type II cells, we postulate that increasing Bmf expression in lung epithelial cells may be an effective approach to block the development of emphysema. 


\section{Materials and Methods}

Animals: Pathogen free $\mathrm{bmf}^{/-}$mice on the C57BL/6 background were previously described (Labi et al., 2008) and were made available by A. Strasser (The Walter and Eliza Hall Institute of Medical Research, Melbourne, Australia). These mice along with the wild-type were bred at the Lovelace Respiratory Research Institute (LRRI) under specific pathogen-free conditions and genotyped as described previously (Labi et al., 2008). All animal experiments were approved by the Institutional Animal Care and use Committee (IACUC) and were performed at LRRI, a facility approved by the Association for the Assessment and Accreditation for Laboratory Animal Care International. Mice were injected intraperitoneally with DMSO (Sigma) or bafilomycin A1 (Santa Cruz) at doses of 0.1 or $2.5 \mathrm{mg} / \mathrm{Kg}$, and 6 or $24 \mathrm{~h}$ later they were humanely euthanized for tissue collection. For the fasting experiments, mice were deprived of food for 12,24 or $30 \mathrm{~h}$ (8 AM to 2 PM next day) with free access to drinking water.

Cell culture: $b \mathrm{ft}^{+/}, \mathrm{bmf}^{+/-}$and $\mathrm{bmf}^{--}$mouse embryonic fibroblasts (MEFs) were isolated from embryonic day 14.5 embryos by trypsin digestion of the remaining tissue after removal of internal organs, brain, and fetal liver. MEFs were cultured in high-glucose version of Dulbecco's modified Eagle's medium (DMEM)(VWR Life Science) supplemented with L-glutamine (Gibco by Life Technologies), penicillin/streptomycin (Gibco by Life Technologies), $0.09 \mathrm{M}$ of 2mercaptoethanol (Sigma) and 10\% FBS (Atlanta Biologicals). MEFs were genotyped as described previously (Labi et al., 2008). $T s c 2^{+/+}$and $T s c 2^{-/}$mouse cells were provided by Elizabeth Henske (Brigham and Women's Hospital, Boston, Massachusetts) and were cultured in high glucose DMEM supplemented with L-glutamine, penicillin/streptomycin, and 10\% FBS. MAECs were prepared essentially as described previously (You, Richer et al., 2002) by incubation in pronase solution $(1.4 \mathrm{mg} / \mathrm{ml}$ pronase and $0.1 \mathrm{mg} / \mathrm{ml}$ DNAse in DMEM) overnight at $4^{\circ} \mathrm{C}$ to dissociate airway epithelial cells from the basal lamina. Cells were collected by gently rocking the tracheas in DMEM/F-12 (Ham) media (Gibco by Life technologies) followed by centrifugation at $400 \mathrm{~g}$ for $10 \mathrm{~min}$ at $4^{\circ} \mathrm{C}$. MAECs were grown in media described previously (Mou, Vinarsky et al., 2016). Two immortalized human airway epithelial cells, N1 and N3, were provided by S. Randell (University of North Carolina Chapel Hill, Chapel Hill, NC) (Fulcher, Gabriel et al., 2005). All airway epithelial cells were driven to differentiation by maintaining them on air-liquid interface culture conditions on Transwell membranes (Corning Incorporated COSTAR). AALEB cells are immortalized HAECs that have been well characterized (Lundberg, Randell et al., 2002). N1, N3 and AALEB cells were maintained in bronchial epithelial growth medium BEGM (Lonza) supplemented with growth factors (BEGM Singlequots, Lonza). Phoenix 
and HEK293T cells were cultured in high-glucose version of DMEM supplemented with Lglutamine, penicillin/streptomycin and 10 \% FBS. Earle's Balanced Salt Solution (EBSS) from Sigma was used as starvation media. The inhibitor pp242 (Sigma) was used at 0.5 or $2.5 \mu \mathrm{M}$ to inhibit mTor kinase activity, MG132 (Sigma) was used at $10 \mu \mathrm{M}$ to inhibit proteasomal degradation, protease inhibitor cocktail (Sigma) was used in all the tissues homogenized and cell lysates.

Polymerase Chain Reaction: Total RNA from cultured cells was extracted by using TriReagent (Molecular Research Center, Inc.) according to the manufacturer's instructions and RNA concentration was determined using a spectrophotometer Nano Drop 1000 (Thermo Scientific). The primer/probe sets for Bmf, CDKN1B, Muc5AC and p62 were obtained from Applied Biosystems. Target mRNAs were amplified by quantitative real time PCR in $20 \mu \mathrm{l}$ reactions on the real-time PCR system 7900HT Sequence Detection System ABI PRISM (Applied Biosystems) using one step TaqMan RT enzyme and TaqMan RT-PCR Mix (Applied Biosystems). Relative quantification from triplicate amplifications were calculated by normalizing averaged threshold cycle $(\mathrm{Ct})$ values to $\mathrm{CDKN} 1 \mathrm{~B}$ to obtain $\Delta \mathrm{Ct}$, and the relative standard curve method was used for determining the fold change.

Retroviral Silencing Using Short Hairpin RNA: Retroviral silencing vector encoding for human Bmf short hairpin RNA (shRNA) and control vector were used. Bmf-specific shRNA plasmids and control plasmids were purchased from OriGene (OriGene Technologies, Inc.) and were packaged into retroviral particles using Phoenix cells as specified by the manufacturer's instructions. The harvested virus was then used to infect cells. To generate stable transfected cells, puromycin (Calbiochem) selection was used according to the manufacturer's instructions. The shRNA knockdown efficiency was confirmed by quantitative RT-PCR.

Cell Survival Assay: Cells were plated in 24-wells plate and when reaching $80-90 \%$ confluency were treated with the regular media (control), $0.5 \mu \mathrm{M}$ pp242 in media, or EBSS (starvation). After $24 \mathrm{~h}$ the cells were washed, trypsinized and the viable cells were counted using Trypan Blue Solution (Sigma). The percent of cell survival was calculated relative to the surviving cells in the control media for each genotype.

Adenoviral infection: Adenoviral expression vectors for GFP and Bmf $\mathrm{CuG}_{\text {were }}$ wreviously described (Contreras et al, 2013). Cells were plated, when reaching $80 \%$ confluence they were infected with adenovirus with 50 or $100, \mathrm{MOI}$ and $24 \mathrm{~h}$ later the infected cells were collected and analyzed. 
Transient Transfection: Transient transfections were carried out with the TransIT-2020 Reagent (Mirus) according to manufacturer's protocol. Plasmid transfected were the following: pRK5-HA-UbiquitinK48 and pRK5-HA-UbiquitinK63 (Addgene plasmids \# 17605 and \#17606 respectively); prcCMV (used as an empty vector, E.v.), prcCMVbcl-2 (expressing wild type Bcl2) and pcrCMVbcl2cb5 (expressing ER localized Bcl-2, ER-Bcl-2) were provided by Elizabeth Osterlund (Sunnybrook Research Institute, Toronto, ON, Canada), Bmf wild type (Bmf in $_{S}$ pShuttle-CMV), BH3 mutant and DBD mutant. The Bmf mutant plasmids BH3 and DBD were generated by Mutagenex Inc. by 4 single-site substitutions to modify the DBD domain from DKATQTLS to DKAAAALS (DBD mutant) and by 3 single-site substitutions to modify the BH3 domain from IARKLQCIADQFHRL to IARKAQCIAAQFHRL (BH3 mutant).

Western Blot Analysis: Fractions of cellular extracts proteins, quantified by Pierce BCA Protein Assay (Thermo Scientific) were mixed with 5x SDS sample buffer (312.5 mM Tris,10\% SDS, $5 \%$ 2-mercaptoethanol, $0.05 \%$ Bromophenol blue and $50 \%$ glycerol; pH 6.8) and subjected to SDS-polyacrylamide gel electrophoresis using Tris/Glycine buffer system based on the method described by Laemmli (Laemmli, 1970). Precision Plus Protein Standards (BioRad) were used in every gel as molecular weight standards. After electrophoresis, proteins were transferred to a nitrocellulose transfer membrane (Bio-Rad). Membranes were blocked, incubated with primary antibody overnight at $4^{\circ} \mathrm{C}$, washed, incubated with peroxidaseconjugated Affini Pure goat anti-rabbit or anti-rat, or rabbit anti-mouse or anti-goat secondary antibody (Jackson Immuno Research Laboratories, Inc.) for 1 hour, washed and visualized by Western Lightning Plus-ECL (Perkin Elmer) according to manufacturer's protocol with the Luminiscent Image Analyzer LAS-4000 (Fujifilm). The following antibodies rabbit anti bak (\#12105), rabbit anti bcl-2 (\#3498 and \#4223), rabbit anti Beclin1 (\#3738), rabbit anti BiP (\#3177), mouse anti CoxIV (\#11967), rabbit anti cytochrome c (\#11940), rabbit anti HA (\#3724), rabbit anti LC3 (\#2775), rabbit anti K48 ubiquitin (\#8081), rabbit anti K63 ubiquitin (\#5621), rabbit anti mitofusin2 (\#9482), rabbit anti phospho-P70S6K (\#9205), rabbit anti ubiquitin (\#3933) were used at 1/1000 dilution and were obtained from Cell Signaling Technologies. Mouse antiactin (A2228) is from Sigma and it was used at 1/4000 dilution. Mouse anti p62 (\#610832) is from B.D. Transduction Labs and it was used in 1/1000 dilution. Rat anti Bmf (17A9) (ALX-804508-C100) is from ENZO and it was used at 1/500 dilution. From Santa Cruz, we obtained rabbit anti DLC1/2 (sc-13969) used in 1/1000 dilution, mouse anti bcl-2 (C-2) (sc-7382) used in 1/300 dilution, mouse anti beclin1 (sc-48341) used in 1/500 dilution, mouse anti GAPDH (sc-32233) used in 1/1000 dilution and rabbit anti GFP (sc-8334) used in 1/500 dilution. 
Agarose Gels for Mucins separation and Western Blot Analysis: Mucin separation was performed in $0.8 \%$ agarose gels as described previously (Ramsey, Rushton et al., 2016), and the transference to Nitrocellulose membranes was performed by capillarity. Membranes were blocked and incubated with primary and secondary antibodies as described in the previous section.

Immunoprecipitation: Cells were lysed with IP Lysis/Wash buffer $(0.025 \mathrm{M}$ Tris, $0.15 \mathrm{M} \mathrm{NaCl}$, 0.001 M EDTA, $1 \%$ NP-40, 5 \% glycerol; pH 7.4) and protein was quantified by BCA Protein Assay Pierce (Thermo Scientific). Between 300 and $500 \mu \mathrm{g}$ of proteins were incubated with $1 \mu \mathrm{g}$ of antibody (when using Santa Cruz or Abcam antibodies) or with the concentration recommended by the manufacturer (when using Cell Signaling antibodies) overnight at $4^{\circ} \mathrm{C}$. Next day, $20 \mu \mathrm{l}$ of Protein A agarose beads (Cell Signaling) were added and incubation continued for $3-5$ hours at $4^{\circ} \mathrm{C}$. Beads were washed with IP Lysis/Wash buffer 5 times and the proteins immunoprecipitated were collected by adding 5x SDS sample buffer. Inputs and immunopecipitations were analyzed by Western Blot. We immunoprecipitated proteins with mouse anti Bcl-2 (C-2) (sc-7382 from Santa Cruz), rabbit anti Beclin1 (ab55878 from Abcam) or mouse anti Beclin1 (sc-48341 from Santa Cruz).

Histology and Morphometry: Mice were euthanized by lethal injection of euthasol, and lungs were inflated and fixed with Zn-formalin at a constant hydrostatic pressure of $25 \mathrm{~cm}$ for $2 \mathrm{~h}$ and further immersed in fixative for $48 \mathrm{~h}$. The inflated lungs were embedded in paraffin and $5 \mu \mathrm{m}$ sagittal sections were stained with Alcian Blue/Hematoxylin-Eosin. Morphometric analysis of alveolar volume measurement was carried out using the Visiomorph module of VisioPharm analysis software (Visiopharm).

Immunofluorescence Assay: bmf $f^{/-}$MEFs cells grown on 2 chamber slide (Lab-Tek II Chamber slide, Thermo Fisher Scientific) were transfected and $24 \mathrm{~h}$ later they were washed 3 times in PBS. The cells were fixed by treatment with 100\% ice-cold methanol (which has been previously kept at $-20^{\circ} \mathrm{C}$ for a minimum of $6 \mathrm{~h}$ ) for $10 \mathrm{~min}$ on ice, according to a described protocol (Mebratu, Leyva-Baca et al., 2017). After fixation, the cells were washed 3 times for 5 min with $2 \%$ BSA in PBS and blocked for $1 \mathrm{~h}$ at RT in the same solution. Cells were incubated with rabbit anti LC3 antibodies (\#2775 from Cell Signaling Technologies, at 1/800 dilution) for overnight at $4^{\circ} \mathrm{C}$. After washing, cells were incubated with secondary antibody (Alexa Fluor 647 $F(a b)$ '2 fragment goat anti-rabbit IgG $(H+L)$ from Invitrogen by Thermo Fisher Scientific) for $2 h$ at room temperature, washed and mounted with DAPI Fluoromount-G (Southern Biotech). Cells were viewed and images were taken by using the $63 x$ oil DIC objective from a Leica DMi8 
inverted confocal microscope and the LASX acquisition software. Images were processed by the Huygens deconvolution software and they were analyzed using the Slidebook 6 software.

$\mathrm{Bmf}^{+/+}, \mathrm{bmf}^{+/-}$and $\mathrm{bmf}^{/-}$MAECs growing on Transwell membranes were washed, fixed with $4 \%$ paraformadehyde for $30 \mathrm{~min}$ at room temperature, washed again and blocked for 1 hour at room temperature in blocking solution (3\% BSA, $1 \%$ gelatin from cold water fish skin, $0.2 \%$ Triton $\mathrm{X}$ $100,0.2 \%$ Saponin and $1 \%$ normal donkey serum in PBS). Cells were incubated with mouse anti Muc5AC (1/500 dilution) overnight in blocking solution at $4^{\circ} \mathrm{C}$. After washing, cells were incubated with secondary antibody (Alexa Fluor 647 F(ab)'2 fragment goat anti-rabbit lgG $(H+$ L) from Invitrogen by Thermo Fisher Scientific) for $2 \mathrm{~h}$ at room temperature, washed and mounted with DAPI Fluoromount-G (Southern Biotech). Cells were viewed and images were taken by using Axioplan 2 (Carl Zeiss) with a Plan Aprochromal 63x/1.4 oil objective and a charge-coupled device camera (SensiCam; PCO), and the acquisition software used was Slide Book 6.0 (Intelligent Imaging Innovation).

Statistical Analysis: Data are presented as means \pm standard errors (SEM). Differences among groups were examined by one-way ANOVA when multiple groups were present or by $\mathrm{t}$ test using Prism Statistical analysis software (GraphPad Software Inc.). A $P$ value of $<0.05$ was considered significant.

\section{Acknowledgements}

These studies were supported by grants from the National Institutes of Health (HL068111 and HL140839).

\section{Author contributions}

YT takes responsibility for the content of the manuscript, including the conception of the study. YT and MD made contributions to the design of the studies. YM, MD, SF, and DT carried out the described experiments, and all authors were involved with acquisition, analysis and interpretation of data and contributed to the writing of the manuscript.

\section{Conflict of interest}

The authors declare that no conflict of interest exists. 
bioRxiv preprint doi: https://doi.org/10.1101/2020.01.02.892828; this version posted January 2, 2020. The copyright holder for this preprint (which was not certified by peer review) is the author/funder. All rights reserved. No reuse allowed without permission. 


\section{References}

Burnett BG, Pittman RN (2005) The polyglutamine neurodegenerative protein ataxin 3 regulates aggresome formation. Proceedings of the National Academy of Sciences of the United States of America 102: 4330-5

Contreras AU, Mebratu Y, Delgado M, Montano G, Hu CA, Ryter SW, Choi AM, Lin Y, Xiang J, Chand H, Tesfaigzi $Y$ (2013) Deacetylation of p53 induces autophagy by suppressing Bmf expression. The Journal of cell biology 201: 427-37

Danial NN, Walensky LD, Zhang CY, Choi CS, Fisher JK, Molina AJ, Datta SR, Pitter KL, Bird GH, Wikstrom JD, Deeney JT, Robertson K, Morash J, Kulkarni A, Neschen S, Kim S, Greenberg ME, Corkey BE, Shirihai OS, Shulman GI et al. (2008) Dual role of proapoptotic BAD in insulin secretion and beta cell survival. Nature medicine 14: 144-53

Danieli A, Martens S (2018) p62-mediated phase separation at the intersection of the ubiquitinproteasome system and autophagy. Journal of cell science 131

Dibble CC, Cantley LC (2015) Regulation of mTORC1 by PI3K signaling. Trends in cell biology 25: 545-55

Dickinson JD, Alevy Y, Malvin NP, Patel KK, Gunsten SP, Holtzman MJ, Stappenbeck TS, Brody SL (2016) IL13 activates autophagy to regulate secretion in airway epithelial cells. Autophagy 12: 397-409

Ekoff M, Kaufmann T, Engstrom M, Motoyama N, Villunger A, Jonsson JI, Strasser A, Nilsson G (2007) The BH3-only protein Puma plays an essential role in cytokine deprivation induced apoptosis of mast cells. Blood 110: 3209-17

Feng W, Zhang W, Wang H, Ma L, Miao D, Liu Z, Xue Y, Deng H, Yu L (2015) Analysis of phosphorylation sites on autophagy proteins. Protein Cell 6: 698-701

Fernandez AF, Barcena C, Martinez-Garcia GG, Tamargo-Gomez I, Suarez MF, Pietrocola F, Castoldi F, Esteban L, Sierra-Filardi E, Boya P, Lopez-Otin C, Kroemer G, Marino G (2017) Autophagy couteracts weight gain, lipotoxicity and pancreatic beta-cell death upon hypercaloric pro-diabetic regimens. Cell death \& disease 8: e2970

Fernandez AF, Sebti S, Wei Y, Zou Z, Shi M, McMillan KL, He C, Ting T, Liu Y, Chiang WC, Marciano DK, Schiattarella GG, Bhagat G, Moe OW, Hu MC, Levine B (2018) Disruption of the beclin 1-BCL2 autophagy regulatory complex promotes longevity in mice. Nature 558: 136-140

Filimonenko $M$, Isakson $P$, Finley KD, Anderson $M$, Jeong $H$, Melia TJ, Bartlett BJ, Myers KM, Birkeland HC, Lamark T, Krainc D, Brech A, Stenmark H, Simonsen A, Yamamoto A (2010) The selective macroautophagic degradation of aggregated proteins requires the PI3P-binding protein Alfy. Molecular cell 38: 265-79

Fulcher ML, Gabriel S, Burns KA, Yankaskas JR, Randell SH (2005) Well-differentiated human airway epithelial cell cultures. Methods Mol Med 107: 183-206

Grespi F, Soratroi C, Krumschnabel G, Sohm B, Ploner C, Geley S, Hengst L, Hacker G, Villunger A (2010) $\mathrm{BH} 3-$ only protein Bmf mediates apoptosis upon inhibition of CAP-dependent protein synthesis. Cell death and differentiation 17: 1672-83

Grice GL, Nathan JA (2016) The recognition of ubiquitinated proteins by the proteasome. Cellular and molecular life sciences : CMLS 73: 3497-506

Hakem R, Hakem A, Duncan GS, Henderson JT, Woo M, Soengas MS, Elia A, de la Pompa JL, Kagi D, Khoo W, Potter J, Yoshida R, Kaufman SA, Lowe SW, Penninger JM, Mak TW (1998) Differential requirement for caspase 9 in apoptotic pathways in vivo. Cell 94: 339-52

Happo L, Strasser A, Cory S (2012) BH3-only proteins in apoptosis at a glance. Journal of cell science 125: 1081-7 
Hillert EK, Brnjic S, Zhang X, Mazurkiewicz M, Saei AA, Mofers A, Selvaraju K, Zubarev R, Linder S, D'Arcy $P$ (2019) Proteasome inhibitor b-AP15 induces enhanced proteotoxicity by inhibiting cytoprotective aggresome formation. Cancer Lett 448: 70-83

Huang DC, O'Reilly LA, Strasser A, Cory S (1997) The anti-apoptosis function of Bcl-2 can be genetically separated from its inhibitory effect on cell cycle entry. The EMBO journal 16: 4628-38

Hubner A, Cavanagh-Kyros J, Rincon M, Flavell RA, Davis RJ (2009) Functional co-operation of the proapoptotic Bcl2-family proteins Bmf and Bim in vivo. Molecular and cellular biology

Innes AL, Woodruff PG, Ferrando RE, Donnelly S, Dolganov GM, Lazarus SC, Fahy JV (2006) Epithelial mucin stores are increased in the large airways of smokers with airflow obstruction. Chest 130: 1102-8

Kuida K, Haydar TF, Kuan CY, Gu Y, Taya C, Karasuyama H, Su MS, Rakic P, Flavell RA (1998) Reduced apoptosis and cytochrome c-mediated caspase activation in mice lacking caspase 9. Cell 94: 325-37

Labi V, Erlacher M, Kiessling S, Manzl C, Frenzel A, O'Reilly L, Strasser A, Villunger A (2008) Loss of the $\mathrm{BH} 3$-only protein Bmf impairs $\mathrm{B}$ cell homeostasis and accelerates gamma irradiation-induced thymic lymphoma development. The Journal of experimental medicine 205: 641-55

Laemmli UK (1970) Cleavage of structural proteins during the assembly of the head of bacteriophage T4. Nature (Lond) 227: 680-5

Levine B, Klionsky DJ (2004) Development by self-digestion: molecular mechanisms and biological functions of autophagy. Developmental cell 6: 463-77

Li J, D'Angiolella V, Seeley ES, Kim S, Kobayashi T, Fu W, Campos El, Pagano M, Dynlacht BD (2013) USP33 regulates centrosome biogenesis via deubiquitination of the centriolar protein CP110. Nature 495: 255-9

Liew SH, Nguyen QN, Strasser A, Findlay JK, Hutt KJ (2017) The ovarian reserve is depleted during puberty in a hormonally driven process dependent on the pro-apoptotic protein BMF. Cell death \& disease 8: e2971

Liew SH, Vaithiyanathan K, Cook M, Bouillet P, Scott CL, Kerr JB, Strasser A, Findlay JK, Hutt KJ (2014) Loss of the proapoptotic $\mathrm{BH} 3$-only protein $\mathrm{BCL}-2$ modifying factor prolongs the fertile life span in female mice. Biology of reproduction 90: 77

Lim GG, Chew KC, Ng XH, Henry-Basil A, Sim RW, Tan JM, Chai C, Lim KL (2013) Proteasome inhibition promotes Parkin-Ubc13 interaction and lysine 63-linked ubiquitination. PloS one 8: e73235

Lin KW, Fang S, Park J, Crews AL, Adler KB (2010) MARCKS and related chaperones bind to unconventional myosin $\mathrm{V}$ isoforms in airway epithelial cells. American journal of respiratory cell and molecular biology 43: 131-6

Linette GP, Li Y, Roth K, Korsmeyer SJ (1996) Cross talk between cell death and cell cycle progression: BCL-2 regulates NFAT-mediated activation. Proceedings of the National Academy of Sciences of the United States of America 93: 9545-52

Lundberg AS, Randell SH, Stewart SA, Elenbaas B, Hartwell KA, Brooks MW, Fleming MD, Olsen JC, Miller SW, Weinberg RA, Hahn WC (2002) Immortalization and transformation of primary human airway epithelial cells by gene transfer. Oncogene 21: 4577-86

Ma XM, Blenis J (2009) Molecular mechanisms of mTOR-mediated translational control. Nature reviews Molecular cell biology 10: 307-18

Maiuri MC, Zalckvar E, Kimchi A, Kroemer G (2007) Self-eating and self-killing: crosstalk between autophagy and apoptosis. Nature reviews Molecular cell biology 8: 741-52

Mebratu YA, Dickey BF, Evans C, Tesfaigzi Y (2008) The BH3-only protein Bik/Blk/Nbk inhibits nuclear translocation of activated ERK1/2 to mediate IFNgamma-induced cell death. The Journal of cell biology 183: 429-39

Mebratu YA, Leyva-Baca I, Wathelet MG, Lacey N, Chand HS, Choi AMK, Tesfaigzi Y (2017) Bik reduces hyperplastic cells by increasing Bak and activating DAPk1 to juxtapose ER and mitochondria. Nat Commun 8: 803 
Mizumura K, Cloonan SM, Nakahira K, Bhashyam AR, Cervo M, Kitada T, Glass K, Owen CA, Mahmood A, Washko GR, Hashimoto S, Ryter SW, Choi AM (2014) Mitophagy-dependent necroptosis contributes to the pathogenesis of COPD. The Journal of clinical investigation

Mizushima N, Yamamoto A, Matsui M, Yoshimori T, Ohsumi Y (2004) In vivo analysis of autophagy in response to nutrient starvation using transgenic mice expressing a fluorescent autophagosome marker. Mol Biol Cell 15: 1101-11

Moreau K, Ravikumar B, Renna M, Puri C, Rubinsztein DC (2011) Autophagosome precursor maturation requires homotypic fusion. Cell 146: 303-17

Mou H, Vinarsky V, Tata PR, Brazauskas K, Choi SH, Crooke AK, Zhang B, Solomon GM, Turner B, Bihler H, Harrington J, Lapey A, Channick C, Keyes C, Freund A, Artandi S, Mense M, Rowe S, Engelhardt JF, Hsu YC et al. (2016) Dual SMAD Signaling Inhibition Enables Long-Term Expansion of Diverse Epithelial Basal Cells. Cell stem cell

Nazio F, Strappazzon F, Antonioli M, Bielli P, Cianfanelli V, Bordi M, Gretzmeier C, Dengjel J, Piacentini M, Fimia GM, Cecconi F (2013) mTOR inhibits autophagy by controlling ULK1 ubiquitylation, self-association and function through AMBRA1 and TRAF6. Nature cell biology 15: 406-16

Olzmann JA, Chin LS (2008) Parkin-mediated K63-linked polyubiquitination: a signal for targeting misfolded proteins to the aggresome-autophagy pathway. Autophagy 4: 85-7

Pattingre S, Tassa A, Qu X, Garuti R, Liang XH, Mizushima N, Packer M, Schneider MD, Levine B (2005) $\mathrm{Bcl}-2$ antiapoptotic proteins inhibit Beclin 1-dependent autophagy. Cell 122: 927-39

Pfeiffer S, Halang L, Dussmann H, Byrne MM, Prehn J (2015) BH3-Only protein bmf is required for the maintenance of glucose homeostasis in an in vivo model of HNF1alpha-MODY diabetes. Cell death discovery 1: 15041

Puthalakath H, Villunger A, O'Reilly LA, Beaumont JG, Coultas L, Cheney RE, Huang DC, Strasser A (2001) Bmf: a proapoptotic $\mathrm{BH} 3$-only protein regulated by interaction with the myosin $\mathrm{V}$ actin motor complex, activated by anoikis. Science 293: 1829-32

Qin H, Gao F, Wang Y, Huang B, Peng L, Mo B, Wang C (2019) Nur77 promotes cigarette smokeinduced autophagic cell death by increasing the dissociation of Bcl2 from Beclin-1. Int J Mol Med 44: 25-36

Raiford KL, Park J, Lin KW, Fang S, Crews AL, Adler KB (2011) Mucin granule-associated proteins in human bronchial epithelial cells: the airway goblet cell "granulome". Respiratory research 12: 118

Ramsey KA, Rushton ZL, Ehre C (2016) Mucin Agarose Gel Electrophoresis: Western Blotting for Highmolecular-weight Glycoproteins. J Vis Exp

Rodriguez I, Araki K, Khatib K, Martinou JC, Vassalli P (1997) Mouse vaginal opening is an apoptosisdependent process which can be prevented by the overexpression of $\mathrm{Bcl}$ 2. Dev Biol 184: 115-21

Roy MG, Livraghi-Butrico A, Fletcher AA, McElwee MM, Evans SE, Boerner RM, Alexander SN, Bellinghausen LK, Song AS, Petrova YM, Tuvim MJ, Adachi R, Romo I, Bordt AS, Bowden MG, Sisson JH, Woodruff PG, Thornton DJ, Rousseau K, De la Garza MM et al. (2014) Muc5b is required for airway defence. Nature 16: 412-6

Schmelzle T, Mailleux AA, Overholtzer M, Carroll JS, Solimini NL, Lightcap ES, Veiby OP, Brugge JS (2007) Functional role and oncogene-regulated expression of the $\mathrm{BH} 3$-only factor Bmf in mammary epithelial anoikis and morphogenesis. Proceedings of the National Academy of Sciences of the United States of America 104: 3787-92

Sha Z, Schnell HM, Ruoff K, Goldberg A (2018) Rapid induction of p62 and GABARAPL1 upon proteasome inhibition promotes survival before autophagy activation. The Journal of cell biology 217: 1757-1776

Shi CS, Kehrl JH (2010a) Traf6 and A20 differentially regulate TLR4-induced autophagy by affecting the ubiquitination of Beclin 1. Autophagy 6: 986-7

Shi CS, Kehrl JH (2010b) TRAF6 and A20 regulate lysine 63-linked ubiquitination of Beclin-1 to control TLR4-induced autophagy. Science signaling 3: ra42 
Shi ZO, Fischer MJ, De Sanctis GT, Schuyler MR, Tesfaigzi Y (2002) IFN-gamma, but not Fas, mediates reduction of allergen-induced mucous cell metaplasia by inducing apoptosis. J Immunol 168: 4764-71

Singer M, Martin LD, Vargaftig BB, Park J, Gruber AD, Li Y, Adler KB (2004) A MARCKS-related peptide blocks mucus hypersecretion in a mouse model of asthma. Nature medicine 10: 193-6

Takahashi M, Kitaura H, Kakita A, Kakihana T, Katsuragi Y, Nameta M, Zhang L, Iwakura Y, Nawa $H$, Higuchi M, Komatsu M, Fujii M (2018) USP10 Is a Driver of Ubiquitinated Protein Aggregation and Aggresome Formation to Inhibit Apoptosis. iScience 9: 433-450

Takeshige K, Baba M, Tsuboi S, Noda T, Ohsumi Y (1992) Autophagy in yeast demonstrated with proteinase-deficient mutants and conditions for its induction. The Journal of cell biology 119: 301-11

Tasdemir E, Maiuri MC, Galluzzi L, Vitale I, Djavaheri-Mergny M, D'Amelio M, Criollo A, Morselli E, Zhu C, Harper F, Nannmark U, Samara C, Pinton P, Vicencio JM, Carnuccio R, Moll UM, Madeo F, PaterliniBrechot P, Rizzuto R, Szabadkai G et al. (2008) Regulation of autophagy by cytoplasmic p53. Nature cell biology 10: 676-87

Tesfaigzi Y, Fischer MJ, Daheshia M, Green FH, De Sanctis GT, Wilder JA (2002) Bax is crucial for IFNgamma-induced resolution of allergen-induced mucus cell metaplasia. J Immunol 169: 5919-25

Tran I, Ji C, Ni I, Min T, Tang D, Vij N (2015) Role of Cigarette Smoke-Induced Aggresome Formation in Chronic Obstructive Pulmonary Disease-Emphysema Pathogenesis. American journal of respiratory cell and molecular biology 53: 159-73

van Rijt SH, Keller IE, John G, Kohse K, Yildirim AO, Eickelberg O, Meiners S (2012) Acute cigarette smoke exposure impairs proteasome function in the lung. American journal of physiology Lung cellular and molecular physiology 303: L814-23

Villunger A, Michalak EM, Coultas L, Mullauer F, Bock G, Ausserlechner MJ, Adams JM, Strasser A (2003) p53- and drug-induced apoptotic responses mediated by $\mathrm{BH} 3-$ only proteins puma and noxa. Science 302: $1036-8$

Wang Z, Zheng T, Zhu Z, Homer RJ, Riese RJ, Chapman HA, Jr., Shapiro SD, Elias JA (2000) Interferon gamma induction of pulmonary emphysema in the adult murine lung. The Journal of experimental medicine 192: 1587-600

Xia P, Wang S, Du Y, Zhao Z, Shi L, Sun L, Huang G, Ye B, Li C, Dai Z, Hou N, Cheng X, Sun Q, Li L, Yang X, Fan Z (2013) WASH inhibits autophagy through suppression of Beclin 1 ubiquitination. The EMBO journal 32: $2685-96$

Xu D, Shan B, Sun H, Xiao J, Zhu K, Xie X, Li X, Liang W, Lu X, Qian L, Yuan J (2016) USP14 regulates autophagy by suppressing K63 ubiquitination of Beclin 1. Genes \& development 30: 1718-30

Yau R, Rape M (2016) The increasing complexity of the ubiquitin code. Nature cell biology 18: 579-86

Yeretssian G, Correa RG, Doiron K, Fitzgerald P, Dillon CP, Green DR, Reed JC, Saleh M (2011) Nonapoptotic role of BID in inflammation and innate immunity. Nature 474: 96-9

Yoshida H, Kong YY, Yoshida R, Elia AJ, Hakem A, Hakem R, Penninger JM, Mak TW (1998) Apaf1 is required for mitochondrial pathways of apoptosis and brain development. Cell 94: 739-50

Yoshida T, Tuder RM (2007) Pathobiology of cigarette smoke-induced chronic obstructive pulmonary disease. Physiological reviews 87: 1047-82

Yoshida Y, Chiba T, Tokunaga F, Kawasaki H, Iwai K, Suzuki T, Ito Y, Matsuoka K, Yoshida M, Tanaka K, Tai $T(2002)$ E3 ubiquitin ligase that recognizes sugar chains. Nature 418: 438-42

Yoshida Y, Tokunaga F, Chiba T, Iwai K, Tanaka K, Tai T (2003) Fbs2 is a new member of the E3 ubiquitin ligase family that recognizes sugar chains. The Journal of biological chemistry 278: 43877-84

Yoshimoto K, Shibata M, Kondo M, Oikawa K, Sato M, Toyooka K, Shirasu K, Nishimura M, Ohsumi Y (2014) Organ-specific quality control of plant peroxisomes is mediated by autophagy. Journal of cell science 127: 1161-8 
You Y, Richer EJ, Huang T, Brody SL (2002) Growth and differentiation of mouse tracheal epithelial cells: selection of a proliferative population. American journal of physiology Lung cellular and molecular physiology 283: L1315-21

Zaffagnini G, Savova A, Danieli A, Romanov J, Tremel S, Ebner M, Peterbauer T, Sztacho M, Trapannone R, Tarafder AK, Sachse C, Martens S (2018) p62 filaments capture and present ubiquitinated cargos for autophagy. The EMBO journal 37

Zhang C, Jones JT, Chand HS, Wathelet MG, Evans CM, Dickey B, Xiang J, Mebratu YA, Tesfaigzi Y (2018) Noxa/HSP27 complex delays degradation of ubiquitylated IkBalpha in airway epithelial cells to reduce pulmonary inflammation. Mucosal Immunol 11: 741-751 


\section{Figure Legends}

\section{Figure 1: Bmf inhibits autophagic initiation and flux}

A) Western blot analysis of protein extracts from $\mathrm{bmf}^{+/}$and $\mathrm{bmf}^{-/}$MEFs treated with DMSO or BAF (50 nM) for $1 \mathrm{~h}$ (left) and graph showing fold change of LC3-II/Actin ( $\mathrm{n}=$ at least 3 independent experiments) (right); ANOVA, * $\mathrm{P}<0.05$. B) Western blot analysis of protein extracts from $b m f^{+/+}$and $b m f^{--}$MAECs (left) and $b m f^{f^{+/}}$and $b m f^{+/-}$MAECs (right) treated with DMSO or BAF (100 nM) for $4 \mathrm{~h}$. C) Quantification of Bmf mRNA from HAEC-N3 cells infected with retroviral constructs with shRNA control (ctr) or sh-Bmf ( $\mathrm{n}=$ at least 3 independent experiments) and Western blot analysis of same cells treated with DMSO or BAF (100 nM) for 4 h (right); T-test, ${ }^{*} \mathrm{P}<0.05$. D) Western blot analysis of protein extracts from $\mathrm{bmf}^{+/+} \mathrm{MAECs}$ infected with AdGFP or AdBmf (MOI: 50) for $24 \mathrm{~h}$ and treated with DMSO or BAF (100 nM) for the last hour (left) and graph showing fold change of LC3-II/Actin ( $n=$ at least 3 independent experiments) (right); ANOVA, ${ }^{*} P<0.05$. E) Western blot anlaysis of protein extracts from HAEC-N3 cells infected with AdGFP or AdBmf (MOI: 50) for $24 \mathrm{~h}$ and treated with DMSO or BAF (100 nM) for the last $4 \mathrm{~h}$. F) Western blot analysis of protein extracts from HEK293T cells transfected with empty vector (E.v.) or $\mathrm{Bmf}_{S}$ expressing plasmid for $24 \mathrm{~h}$ and treated with DMSO or BAF $(100 \mathrm{nM})$ for the last $4 \mathrm{~h}$. G) Western blot analysis of protein extracts from the heart lysates $\left(100 \mathrm{\mu g}\right.$ or proteins) from naive $56 \mathrm{wks}$ old male $\mathrm{bmf}^{+/+}, \mathrm{bmf}^{-/}$, and $\mathrm{bmf}^{--}$mice.

\section{Figure 2: Bmf inhibits autophagy independent of the mTor pathway}

A) Western blot analysis of protein extracts from $b \mathrm{ff}^{f^{++}}$and $b \mathrm{mf}^{f^{+-}}$MAECs treated with pp242 $(0.5 \mu \mathrm{M})$ and DMSO or BAF $(100 \mathrm{nM})$ for $4 \mathrm{~h}$. B) Western blot analysis of protein extracts from ${b m f^{+/+}}$and $b m f^{+-}$MAECs in full media (Fed) or EBSS (Starvation) for $1 \mathrm{~h}$ in the presence of BAF (100 nM). C) Western blot of $T s c 2^{-/}$mouse cells infected with AdGFP or AdBmf (MOI: 50) for $24 \mathrm{~h}$ and treated with DMSO or BAF $(50 \mathrm{nM})$ for the last $4 \mathrm{~h}$. D) Western blot analysis of protein extracts from $b \mathrm{mf}^{+/+}$MAECs infected with AdGFP or AdBmf (MOI: 50) for $24 \mathrm{~h}$ and treated with pp242 $(0.5 \mu \mathrm{M})$ for $4 \mathrm{~h}$ and BAF $(100 \mathrm{nM})$ for the last hour. E) Western blot analysis of protein extracts from HAEC-N3 cells infected with AdGFP or AdBmf (MOI: 50) for $24 \mathrm{~h}$ and treated with DMSO or pp242 $(2.5 \mu \mathrm{M})$ for the last $4 \mathrm{~h}$. F) Quantification of Bmf mRNA from $\mathrm{bmf}^{+/+}$MAECs (left) or HAEC-N3 (right) treated with full media (F), pp242 $(0.5 \mu \mathrm{M}$ for MAECs and $2.5 \mu \mathrm{M}$ for HAEC-N3) or EBSS (starvation, St) for $24 \mathrm{~h}$ and analyzed by qPCR ( $\mathrm{n}=$ at least 3 independent experiments; ANOVA, * $\mathrm{P}<0.05)$. G) Quantification of Bmf mRNA from $b m f^{+/+}$and $b m f^{+/-}$MAECs 
treated with full media (Fed), pp242 $(0.5 \mu \mathrm{M})$ or EBSS (starvation, Starv) for $4 \mathrm{~h}$ and analyzed by qPCR. ( $\mathrm{n}=$ at least 3 independent experiments; ANOVA, ${ }^{*} \mathrm{P}<0.05$ ). H) Quantification of

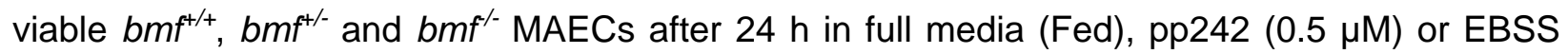
(starvation, Starv) by Trypan blue exlusion assay ( $\mathrm{n}=$ at least 3 independent experiments; ANOVA, * $\mathrm{P}<0.05)$. I) Representative images (left) and morphometric analysis for volume weighted mean alveolar volume (right) of lungs inflated and fixed with formalin under constant pressure, $n=3$ mice per group (8 wks old male mice); ANOVA, ${ }^{*} P<0.05$. J) Percentage of body weight after fasting $\mathrm{bmf}^{+/+}$and $\mathrm{bmf}^{--}$mice for $30 \mathrm{~h}$, relative to the body weight before start the fasting period, $n=6$ mice per genotype ( 3 males and 3 females 9-10 wks old mice); unpaired Ttest for each time point, ${ }^{\star} P<0.05$.

\section{Figure 3: Bmf enhances proteasomal degradation}

A) Western blot analysis of protein extracts from $b m f^{+/+}, b m f^{+/}$and $b m f^{--}$MAECs. B) Western blot analysis of protein extracts from $b f^{+/+}, b m f^{+-}$and $b m f^{/-}$MAECs infected with AdGFP or AdBmf for $24 \mathrm{~h}$ (MOI: 50). C) Western blots analysis of protein extracts from the lung cranial lobe lysates (100 $\mu \mathrm{g}$ of proteins) from male mice at 8 and 56 weeks of age. D) Western blots analysis of protein extracts from $b m f^{++}$and $b m f^{+-}$MAECs treated with DMSO or MG132 (10 $\left.\mu \mathrm{M}\right)$ for $6 \mathrm{~h}$. E) Western blots of the "insoluble" fraction from $b m f^{+/+}$and $b m f^{+-}$MAECs. F) Western blot of the "soluble" and "insoluble" fractions from the left lung (100 $\mu \mathrm{g}$ of proteins) from 56 wks old male mice. G) Western blot of $b m f^{+/}, b m f^{+/}$and $b m f^{/-}$MAECs treated with DMSO and $b m f^{+/+}$ MAECs treated with MG132 (10 $\mu \mathrm{M})$ for $6 \mathrm{~h}$ (left) and graph showing ubiquitinated proteins/Actin fold change, $n=$ at least 3 independent experiments (right); ANOVA, ${ }^{*} P<0.05$. H) Western blot of $\mathrm{bmf}^{+/+}, \mathrm{bmf}^{+-}$and $\mathrm{bmf}^{-/}$MAECs. I) Western blot of HEK293T cells either not transfected, transfected with HA-K48-Ubiquitin, or with $\mathrm{HA}-\mathrm{K} 48$-Ubiquitin and $\mathrm{Bmf}_{\mathrm{S}}$-expressing plasmids. J) Western blot of the "soluble" and "insoluble" fractions from the left lung from 56 wks old male mice and probed for K48-Ubiquitin and actin.

Figure 4: Bmf affects proteasomal degradation of mucins in mice and in differentiated MAECs

A) Mucous cells per $\mathrm{mm}$ of basal lamina in lungs from $\mathrm{bmf}^{+/+}$and $\mathrm{bmf}^{/-}$mice after 5 or 15 days of OVA exposure, $\mathrm{n}=5$ mice per genotype ( 4 males and 1 female $b m f^{+/+}$and 2 males and 3 females $\mathrm{bmf}^{-}$mice); unpaired T-test, ${ }^{*} \mathrm{P}<0.05$. B) Immunofluorescence for Muc5ac in 
differentiated $\mathrm{bmf}^{+/+}$and $b m f^{+-}$MAECs treated with IL-13 $(10 \mathrm{ng} / \mathrm{ml})$ for 14 days and kept without treatment for an additional 7 days period. C) Quantification of Muc5ac mRNA from differentiated $\mathrm{bmf}^{+/+}, \mathrm{bmf}^{+/}$and $\mathrm{bmf}^{--}$MAECs in control media and analyzed by qPCR. D) Protein extracts prepared from differentiated $\mathrm{bmf}^{+/+}$and $\mathrm{bmf}^{--}$MAECs in control media (control) or 7 days in control media post 14 days of $10 \mathrm{ng} / \mathrm{ml} \mathrm{IL-13}$ treatment $(\mathrm{IL}-13+7 \mathrm{~d})$ and analyzed by Western blotting after agarose gel electrophoresis using anti Muc5ac and anti Ubiquitin antibodies. E) Protein extracts prepared from differentiated $\mathrm{bmf}^{+/+}$and $\mathrm{bmf}^{-/}$MAECs in control media (control), treated with $10 \mathrm{ng} / \mathrm{ml} \mathrm{IL-13}$ for 14 days (IL-13) or 7 days post IL-13 treatment $(\mathrm{IL}-13+7 \mathrm{~d})$ and analyzed by Western blotting after agarose gel electrophoresis using anti K-48Ubiquitin antibodies. F) Western blot analysis of protein extracts from differentiated $\mathrm{bmf}^{+/+}$and bmf $^{/-}$MAECs in control media and developed with anti CoxIV, Cytochrome c (Cyt c), Bak and Actin antibodies.

\section{Figure 5: Bmf inhibits autophagy by decreasing K63 ubiquitination of Beclin1}

A) Immunoprecipitation of protein extracts from $b m^{+/+}$and $b m f^{+/-}$MAECs using anti Beclin1 antibodies and Western blot analysis of inputs and immunoprecipitated (IP) proteins. The ratio $\mathrm{Bcl}-2 /$ Beclin1 in the immunoprecipitates is shown. B) Immunoprecipitation of protein extracts from bmf ${ }^{\prime-}$ MAECs infected with AdGFP or AdBmf (MOI: 100) for $24 \mathrm{~h}$ using anti Beclin1 antibodies. Western blot analysis of inputs and immunoprecipitated (IP) proteins with calculated $\mathrm{Bcl}-2 /$ Beclin1 ratio. C) Western blot of $\mathrm{bmf}^{+/+}$and $\mathrm{bmf}^{+/-}$MAECs treated with ABT-263 (0.5 $\left.\mu \mathrm{M}\right)$ for $5 \mathrm{~h}$ and BAF (100 $\mathrm{nM}$ ) for the last hour (left) and graph showing the fold change of LC3II/Actin, $n=$ at least 3 independent experiments (right); ANOVA, ${ }^{*} P<0.05$. D) Western blot analysis of protein extracts from $\mathrm{bmf}^{+/+}$and $\mathrm{bmf}^{+/-}$MAECs treated with DMSO or MG132 (10 $\left.\mu \mathrm{M}\right)$ for $6 \mathrm{~h}$ (left) and graph showing the fold change of LC3-II/Actin, $\mathrm{n}=$ at least 3 independent experiments (right). E) Western blot analysis of $\mathrm{bmf}^{+/+}, \mathrm{bmf}^{+/}$and $\mathrm{bmf}^{\mathrm{f}^{-}}$MAECs for total K-63 ubiquitinated proteins and actin. F) Proteins extracted from non-transfected HEK293T cells and those transfected with HA-K63-Ubiquitin or co-transfected with both HA-K63-Ubiquitin and Bmf expressing plasmids and analyzed by Western blotting. G) Western blot analysis of the "soluble" and "insoluble" fractions from the left lung of male mice at 56 wks of age. H) Immunoprecipitation of protein extracts from $\mathrm{bmf}^{+/+}$and $\mathrm{bmf}^{+/-}$MAECs using anti Beclin1 antibodies. Western blot analysis of inputs and immunoprecipitated (IP) proteins. I) Immunoprecipitation using anti Beclin1 antibodies of protein extracts from bmf $\mathrm{bmECs}^{/-}$non 
transfected or transfected with a $\mathrm{Bmf}_{S}$ expressing plasmid, inputs and immunoprecipitated (IP) proteins analyzed by Western blot. The calculated K63-Ubiquitin/Beclin1 ratio is shown.

\section{Figure 6: Domains of Bmf protein important for its role on K63-ubiquitination and autophagy}

A) Amino acid sequences of the dynein binding domain (DBD) and the BH3 only domain of the mouse wild type $\mathrm{Bmf}_{\mathrm{S}}$ protein and the introduced amino acids mutations in the DBD and the BH3 mutants. B) Western blot analysis of protein extracts from HEK293T cells transfected with control plasmid (Empty vector, E.v.), or those expressing wild type $\mathrm{Bmf}_{S}$ (wt), and the $\mathrm{BH} 3$ or DBD mutants. C) Proteins from HEK293T cells co-transfected with HA-K63-Ubiquitin and control (Empty vector, E.v.) or $\mathrm{Bmf}_{\mathrm{S}}$ (wild type and mutants) expressing plasmids were analyzed by Western blotting. D) Immunoprecipitation of protein extracts from HEK293T cells cotransfected with HA-K63-Ubiquitin and E.v., wild type (wt) Bmf or BH3 and DBD mutants using anti Beclin1 antibodies. Western blot analysis of inputs and immunoprecipitated (IP) proteins. E) $B m f^{\prime-}$ MEFs transfected with E.v., wt, or the BH3 and DBD mutants plasmids developed with anti LC3 and anti Actin antibodies. F) Representative immunofluorescent images of $\mathrm{bmf}^{-/}$MEFs transfected with the E.v, wt, or BH3 and DBD mutant plasmids and immunostained with anti LC3 and Cy5 antibodies (left) and quantification of punctuated LC3 of 23-48 cells from each transfection (ANOVA, * $\mathrm{P}<0.05)$. 
bioRxiv preprint doi: https://doi.org/10.1101/2020.01.02.892828; this version posted January 2, 2020. The copyright holder for this preprint (which was not certified by peer review) is the author/funder. All rights reserved. No reuse allowed without permission.
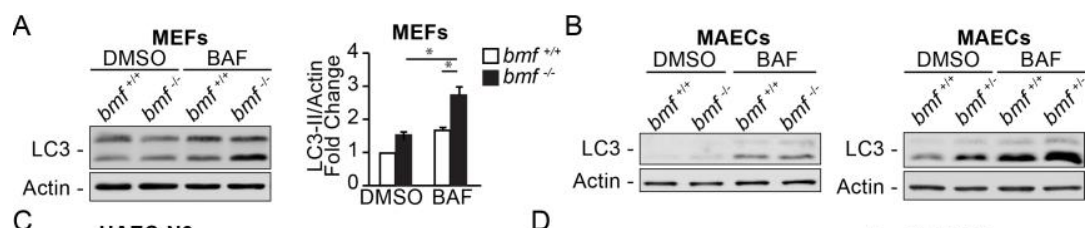

C
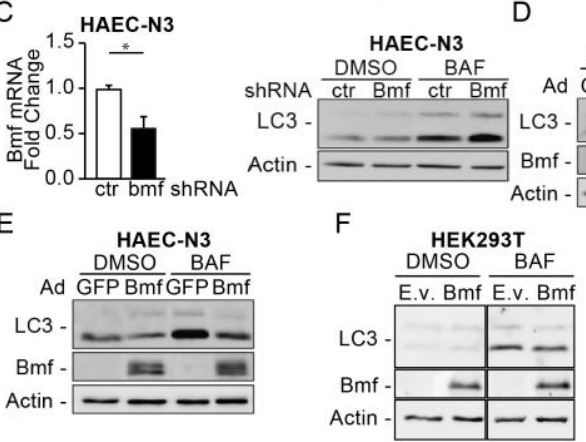

bmf $f^{\prime+}$ MAECs

$\frac{\mathrm{DMSO}}{\mathrm{GFPBmf}} \frac{\mathrm{BAF}}{\mathrm{GFPBmf}}$

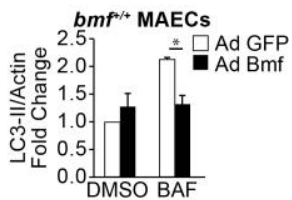

G

Heart (56 wks)

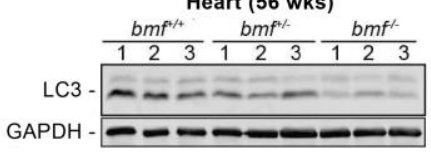

Figure 1 


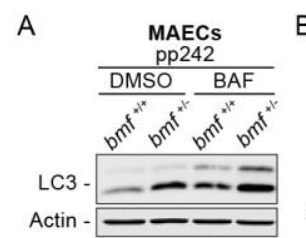

$\mathrm{F}$

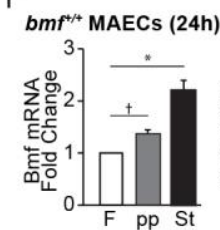

I
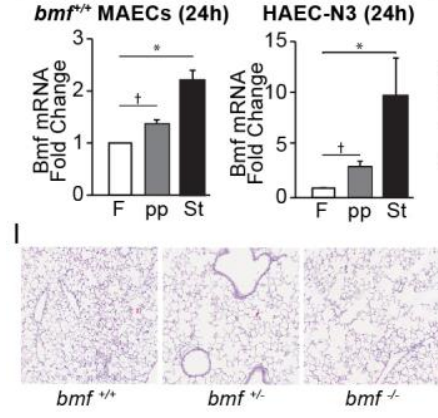

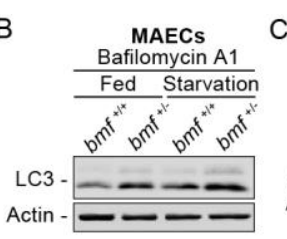

G

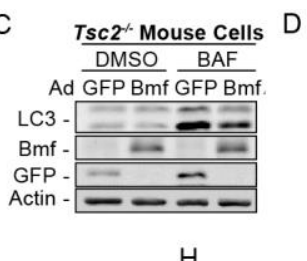

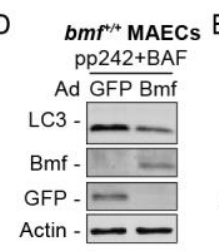

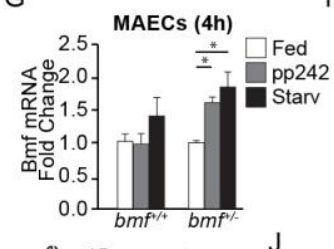

140 MAECS
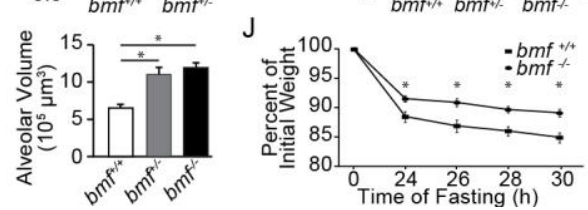

Figure 2 
bioRxiv preprint doi: https://doi.org/10.1101/2020.01.02.892828; this version posted January 2, 2020. The copyright holder for this preprint (which was not certified by peer review) is the author/funder. All rights reserved. No reuse allowed without permission.
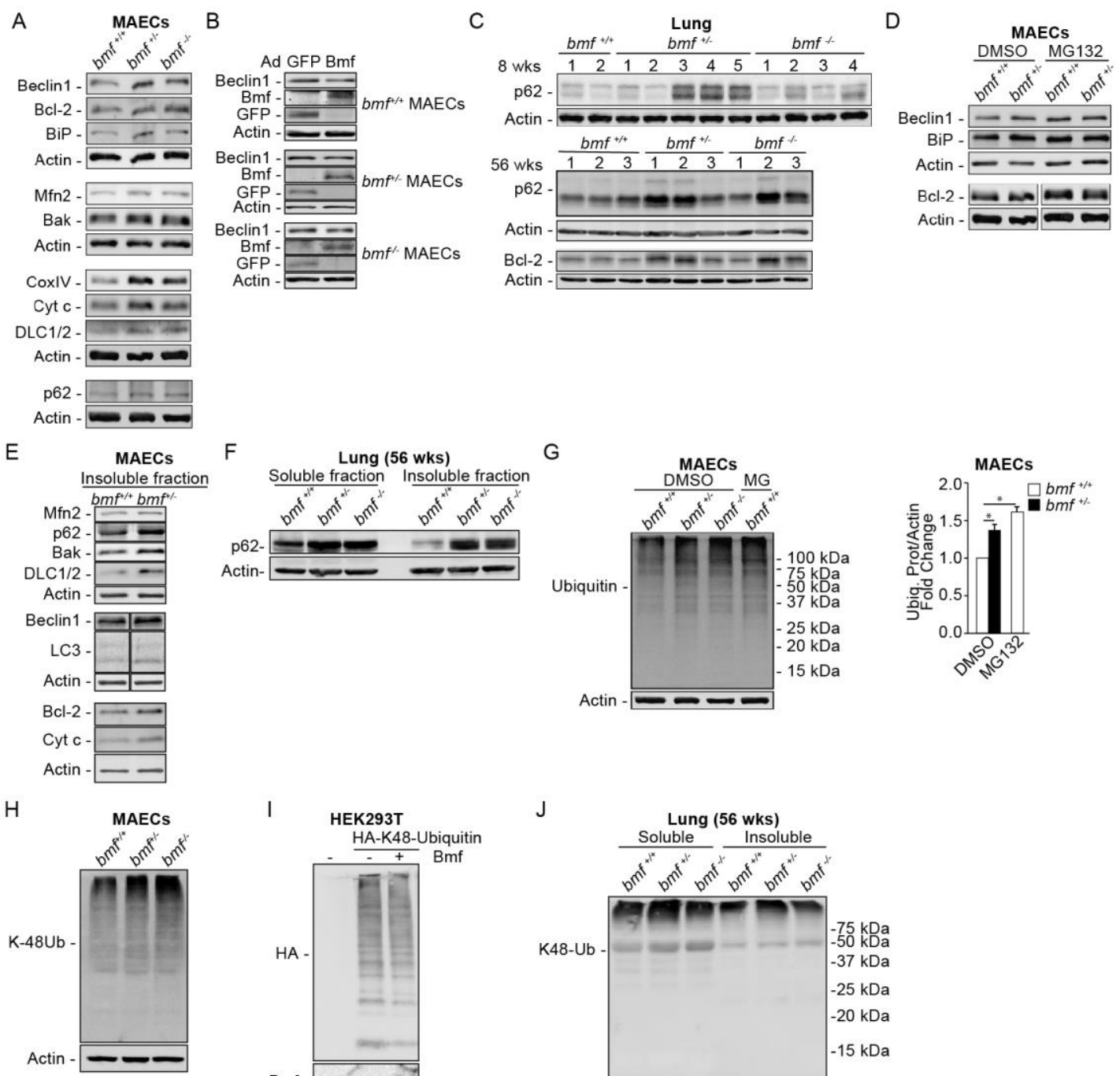

\section{Figure 3}
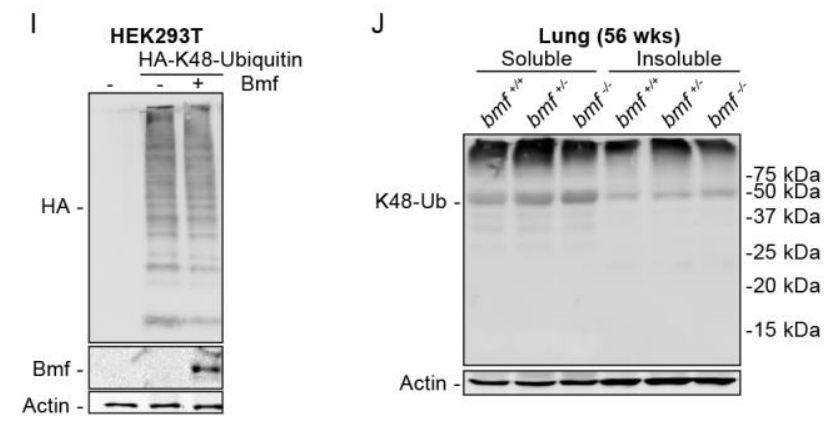
bioRxiv preprint doi: https://doi.org/10.1101/2020.01.02.892828; this version posted January 2, 2020. The copyright holder for this preprint (which was not certified by peer review) is the author/funder. All rights reserved. No reuse allowed without permission.
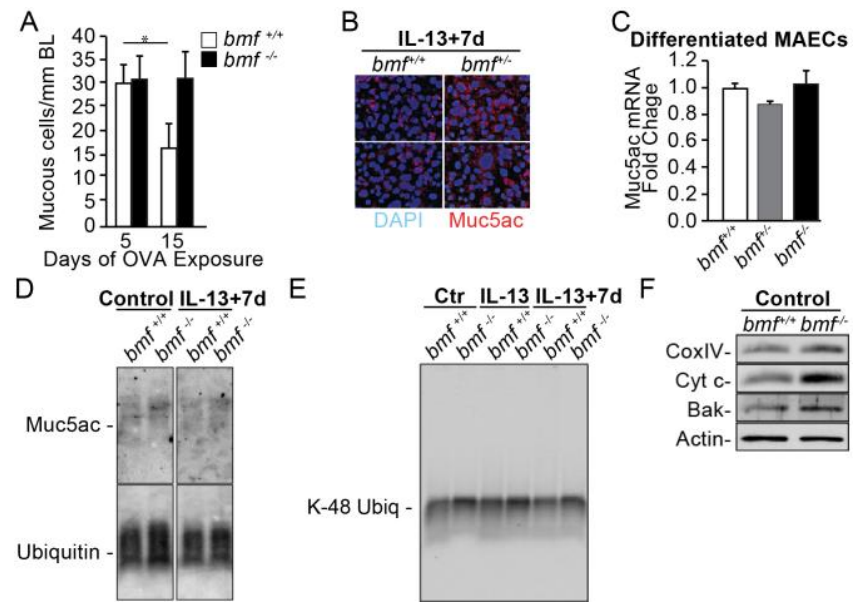

Figure 4 
bioRxiv preprint doi: https://doi.org/10.1101/2020.01.02.892828; this version posted January 2, 2020. The copyright holder for this preprint (which was not certified by peer review) is the author/funder. All rights reserved. No reuse allowed without permission.

A

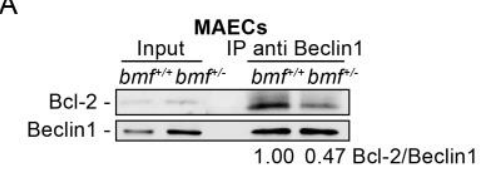

B

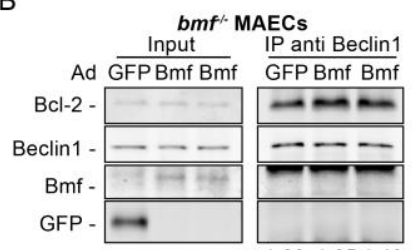

C

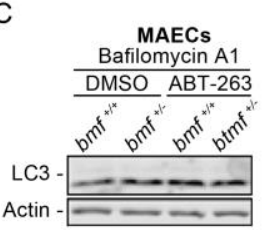

E

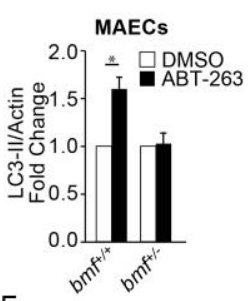

D

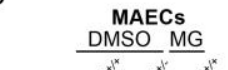

$1.001 .651 .49 \mathrm{Bcl}-2 / \mathrm{Beclin} 1$

LC3
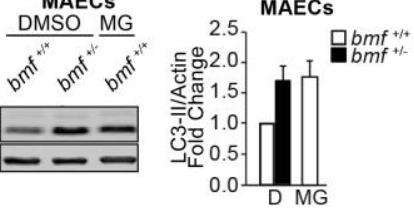

G

Lung (56 wks)

F HEK293T HA-K63-Ubiquitin
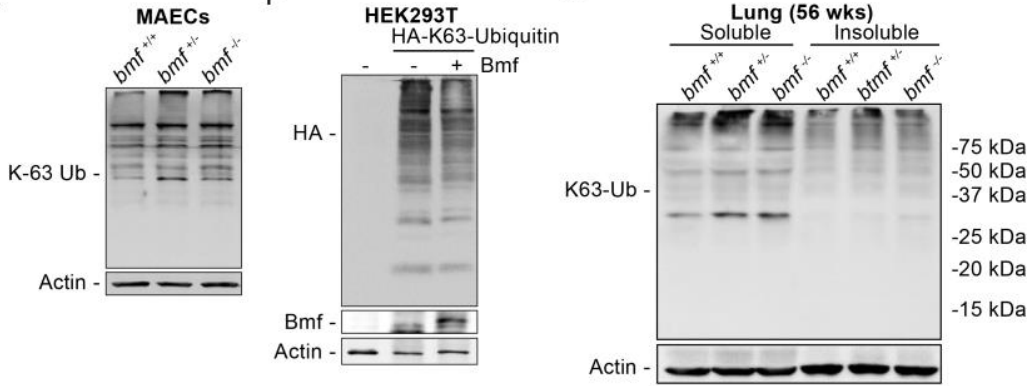

$\mathrm{H}$

MAECs

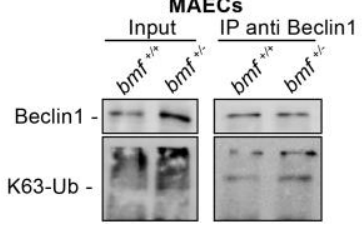

।

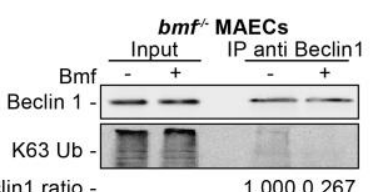

K63 Ub/Beclin1 ratio

\section{Figure 5}


bioRxiv preprint doi: https://doi.org/10.1101/2020.01.02.892828; this version posted January 2, 2020. The copyright holder for this preprint (which was not certified by peer review) is the author/funder. All rights reserved. No reuse allowed without permission.

A

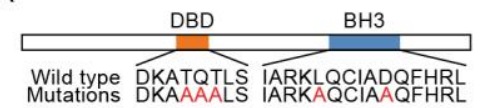

B

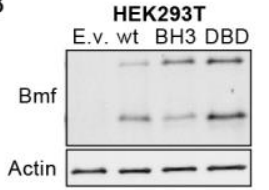

C

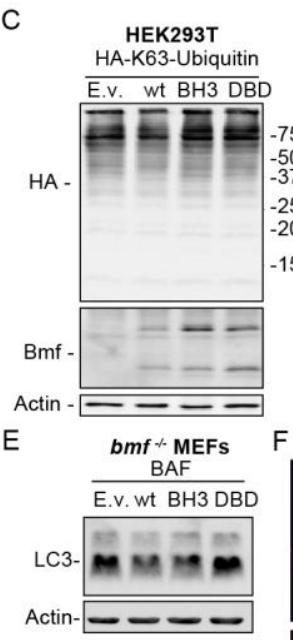

D

Input HEK293T Input $\frac{\text { IP anti Beclin1 }}{\text { HA-K63-Ubiquitin }}$

$75 \mathrm{kDa}$

$-50 \mathrm{kDa}$

$-37 \mathrm{kDa}$

$20 \mathrm{kDa}$

$15 \mathrm{kDa}$

Beclin1 - - -

Bcl-2 -
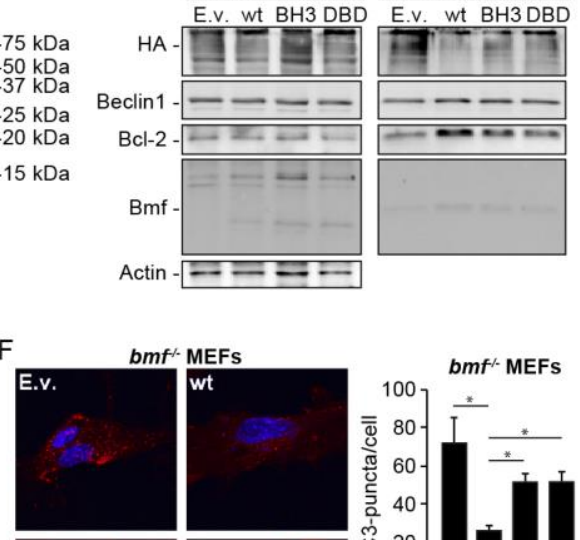

BH3

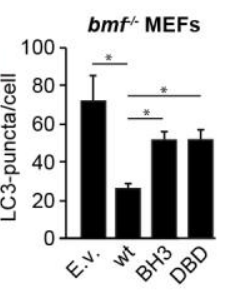

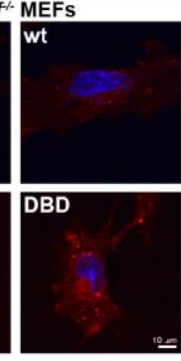

Figure 6 